\title{
Activated PI3Kס syndrome, an immunodeficiency disorder, leads to sensorimotor deficits recapitulated in a murine model.
}

Ines Serra ${ }^{*}$, Olivia R. Manusama ${ }^{*}$, Fabian M. P. Kaiser²,3, Izi Izumi Floriano ${ }^{1}$, Lucas Wahl'1, Christian van der Zalm¹, Hanna IJspeert², P. Martin van Hagen²,4, Nico J.M. van Beveren Sandra M. Arend ${ }^{6}$, Klaus Okkenhaug ${ }^{7}$, Johan J.M. Pel ${ }^{1}$, Virgil A.S.H. Dalm²,4,8 and Aleksandra Badura $^{1}$

${ }^{1}$ Department of Neuroscience, Erasmus MC, Rotterdam, The Netherlands

${ }^{2}$ Department of Immunology, Erasmus MC, Rotterdam, The Netherland

${ }^{3}$ Department of Pediatrics, Erasmus MC, Rotterdam, The Netherlands

${ }^{4}$ Division of Clinical Immunology, Department of Internal Medicine, Erasmus MC, Rotterdam, The Netherlands

${ }^{5}$ Department of Psychiatry, Erasmus MC, Rotterdam, The Netherlands

${ }^{6}$ Department of Infectious Diseases, Leiden University Medical Center, Leiden, The Netherlands

${ }^{7}$ Department of Pathology, University of Cambridge, Cambridge, United Kingdom ${ }^{8}$ Academic Center for Rare Immunological Diseases (RIDC), Erasmus MC, Rotterdam, The Netherlands

Correspondence: Aleksandra Badura (a.badura@erasmusmc.nl) Department of Neuroscience, Erasmus MC Wytemaweg 80, 3015 CN Rotterdam tel: 0031-(0)10-7043309

Conflict of interest statement: $\mathrm{PMH}$ has received grants and research support from Takeda, CSL Behring, Abbvie, Lamepro, Novartis Nederland, and honoraria or consultation fees from UCB Pharma. The other authors have no conflict of interest to declare. 


\section{Abstract}

2

3 The phosphoinositide-3-kinase ( $\mathrm{PI} \mathrm{KK}$ ) family plays a major role in cell signalling and is 4 predominant in leukocytes. Gain-of-function (GOF) mutations in the PIK3CD gene lead to the 5 development of activated PI3Kס syndrome (APDS), a rare primary immunodeficiency disorder.

6 A subset of APDS patients also displays neurodevelopmental delay symptoms, suggesting a 7 potential role of $P I K 3 C D$ in cognitive and behavioural function. However, the extent and nature 8 of the neurodevelopmental deficits has not been previously quantified. Here, we assessed the 9 cognitive functions of two APDS patients, and investigated the causal role of the PIK3CD GOF mutation in neurological deficits using a murine model of this disease. We used E1020K knock-in mice, harbouring the most common APDS mutation in patients. We found that APDS patients present with visuomotor deficits, exacerbated by autism spectrum disorder comorbidity, whereas $\mathrm{p} 110 \delta^{\mathrm{E} 1020 \mathrm{~K}}$ mice exhibited impairments in motor behaviour, learning and repetitive behaviour patterning. Our data indicate that PIK3CD GOF mutations increase the risk for neurodevelopmental deficits, supporting previous findings on the interplay between the nervous and the immune system. Further, our results validate the knock-in mouse model, and offer an objective assessment tool for patients that could be incorporated in diagnosis and in the evaluation of treatments. 


\section{Introduction}

Primary immunodeficiencies (PID) encompass a group of heterogeneous, mostly inheritable, disorders that affect distinct components of the immune system $(1,2)$. Common manifestations of PID include increased susceptibility to infection, autoimmune disease, autoinflammatory complications and malignancies, ultimately leading to increased morbidity and mortality rates (3-6). Activated PI3K delta (PI3Kס) syndrome (APDS) is a rare monogenic PID, caused by heterozygous mutations in either the PIK3CD or PIK3R1 genes, encoding the $\mathrm{p} 110 \delta$ catalytic subunit or the $\mathrm{p} 85 \alpha$ regulatory subunit of PI3Kס, respectively (7). The most commonly detected variants in APDS patients are the E1021K substitution in p110ס, leading to APDS1, and the 434-475 deletion in p85a, resulting in APDS2 $(8,9)$. Both mutations lead to gain-of-function (GOF) of PI3Kס and overactivation of the downstream AKT/mTOR cascade (10-13). In the immune system, PI3Kס GOF leads to skewed B cell populations towards a transitional phenotype, decreased numbers of naïve T cells and increased senescent T cells, resulting in impaired vaccine responses and overall immune dysfunction $(11,14,15)$. Consequently, APDS patients present with recurrent infections, lymphoproliferation, autoinflammatory disease and lymphoma $(8,9)$.

Although predominantly expressed in peripheral blood mononuclear cells (16), PI3Kס is also detected in murine $(12,17)$ and human $(12,18)$ brain tissue. In the CNS, the $\mathrm{PI} 3 \mathrm{~K} / \mathrm{AKT} / \mathrm{mTOR}$ axis has been shown to play a crucial role in neuronal differentiation and migration $(19,20)$. Accordingly, mutations along this pathway have been commonly associated with neurodevelopmental and neuropsychiatric disorders (21). Although few studies have focused on the specific role of distinct PI3K isoforms in the CNS, PI3Kס has been proposed to regulate soma size, dendritic complexity and spine number $(12,22,23)$, suggesting a contributing role towards neuronal morphology. Interestingly, $19-31 \%$ of APDS patients were reported to exhibit neurodevelopmental delay $(8,9)$. However, the lack of systematic cognitive evaluation in these reports hinders the quantitative study of $\mathrm{PI} 3 \mathrm{~K} \delta$ on neurological function. Nonetheless, this putative behavioural role of PI3Kס is further implied by the report of increased p110ס expression in a person with autism spectrum disorder (ASD) (24). 
In this work, we investigated the role of PI3Kס in motor and cognitive behaviour. We

58 describe two related APDS patients and report, for the first time, a case of APDS-associated

59 ASD. APDS patients presented with deficits in visuomotor integration, particularly in inhibition-

60 recruiting and memory tasks, accentuated by the ASD phenotype in one of them. Additionally,

61 we conducted an extensive battery of behavioural tests in an APDS mouse model (11), and

62 show that $\mathrm{p} 110 \delta^{\mathrm{E} 1020 \mathrm{~K}}$ mice present with changes in locomotion, learning and repetitive

63 behaviour patterning. Taken together, our data suggest that PI3Kס GOF increases the risk of

64 atypical behavioural development, supporting previous findings on the interplay between the

65 CNS and the immune system.

66

67

68 
Results

\section{Immunological profile and neuropsychiatric manifestations of APDS patients}

72

We present a 29-year-old male patient, $\mathrm{P} 1$, the second child of non-consanguineous parents of Caucasian descent (P2) (Table 1, 2) (15). Since the age of 9 months, P1 suffered from recurrent upper and lower respiratory tract infections and diarrhoea. At the age of 3.5 years, P1 was hospitalized for generalized lymphadenopathy due to EBV infection. He was subsequently diagnosed with common variable immunodeficiency, based on low serum IgG and $\lg \mathrm{A}$ levels (with elevated $\lg \mathrm{M}$ levels), and recurrent infectious complications for which intravenous immunoglobulin replacement therapy was initiated. At the age of $7, \mathrm{P} 1$ developed auto-immune complications, including cutaneous manifestations, fever, arthritis, anaemia, thrombocytopenia and hepatosplenomegaly, with positive antinuclear antibody and antidsDNA titres, described as systemic lupus erythematosus (SLE)-like disease, for which immunosuppressive therapy was initiated. Other complications included liver cirrhosis due to auto-immune hepatitis with portal hypertension, requiring liver transplantation in December 2020. At age 22, genetic testing revealed a c.3061 G>A mutation in the PIK3CD gene, resulting in an E1021K substitution and APDS1 $(25,26)$.

Besides this immunological phenotype, we also observed neuropsychological deficits in P1. Psychomotor developmental delay was present, as the patient started walking at the age of 2 and speaking at age 2.5. At age 6, ASD was considered and P1 was referred to special needs education. At the age of 9 years, intelligence quotient testing indicated a score of 80 . Moreover, P1 showed persistent deficits in social interaction, motor function and a distinct fascination for watches, calendars and dates. P1 was diagnosed with pervasive developmental disorder not otherwise specified at age 10, and re-evaluation in 2020 confirmed the diagnosis of ASD based on psychiatric examination and on the autism-spectrum quotient (27). To date, P1 requires assistance with tying shoelaces and buttoning his shirts. 
Patient 2 (P2), who has been previously described (15), is a non-consanguineous

parent from P1. Genetic testing revealed a c. $3061 \mathrm{G}>\mathrm{A}$ mutation in the PIK3CD gene, resulting

in the E1021K substitution, which was also found in P1. P2 suffered from recurrent upper and

lower respiratory tract infections since childhood and was diagnosed with an IgG2 and IgG4

subclass deficiency. She then commenced immunoglobulin replacement therapy and has

been on intravenous treatment since. A recent CT-scan showed bronchiectasis. There have

been no signs of hepatosplenomegaly nor lymphadenopathy. Currently, her clinical phenotype

is relatively mild, with no recurrence of severe infections, no auto-immune complications, no

inflammatory disease and no haematological malignancy. She was never diagnosed with a neurodevelopmental condition.

\section{APDS patients present with deficits in visuomotor integration}

Previous clinical descriptions of APDS reported the presence of cognitive impairment, developmental delay or speech delay in a number of patients $(8,9)$. Given the formal diagnosis of ASD in P1, and its association with attention and motor performance (28-30), we conducted a series of tests to evaluate visuomotor performance in both patients (Fig. 1a-c).

$114(31,32)$, was intact in both patients, with performance in the pro-saccade test equal between

115 P1, P2 and their respective age-matched controls (performance: 100\% for all groups) (Fig.

116 2a). While pro-tapping performance was also similar for all cohorts (performance: $100 \%$ for all

117 groups), P1 exhibited increased hand latency compared to the other groups. Specifically, P1

118 average latency was over 4.5 SD higher than the age-matched control group (C1) (P1 = 463

$119 \mathrm{~ms}, \mathrm{C} 1=391 \pm 16 \mathrm{~ms}, \mathrm{P} 2=400 \mathrm{~ms}, \mathrm{C} 2=403 \pm 33 \mathrm{~ms}$ ) (Fig. 2a, c).

To understand whether this increased hand latency was due to a motor impairment or rather a consequence of increased task complexity, motor command and execution were tested in the trajectory prediction test (Fig. 1c). Both patients exhibited similar latencies in 
$124(\mathrm{P} 1=513 \mathrm{~ms} ; \mathrm{P} 2=570 \mathrm{~ms} ; \mathrm{C}=539 \mathrm{~ms})$. Average hand latency was also similar for both $\mathrm{P} 1$

125 and P2 when compared to control groups, suggesting intact preparation and onset of motor 126 response $(\mathrm{P} 1=779 \mathrm{~ms} ; \mathrm{P} 2=761 \mathrm{~ms} ; \mathrm{C}=767 \mathrm{~ms})$. However, while P2 exhibited similar 127 performance to controls, $\mathrm{P} 1$ presented with a reduction in the percentage of correct trials (P1 $128=78 \%, \mathrm{P} 2=100 \%, \mathrm{C}=96 \%$ ) (Fig. 2f). Moreover, both APDS patients adopted a less systematic strategy to follow the ball's trajectory compared to controls, exhibiting less goaldirected scan paths and more irregular eye gaze (Fig. 2f). These data suggest that, while preparation and onset of motor responses appear to be intact in both patients, increased task speed and complexity likely impairs integration, particularly in P1.

We next tested volitional inhibitory behaviour using the anti-saccade and anti-tapping tests (Fig.1a, b). Both tests require a suppression of reflexive pro-saccades and engage a complex network of brain regions, including dorsolateral prefrontal cortex, frontal eye fields, and supplementary eye fields, basal ganglia, superior colliculus and cerebellum (33-35). The anti-saccade task has been used to characterize cognitive impairments in patients with schizophrenia $(36,37)$, dementia (38), Parkinson's disease (39) and cerebellar atrophies (40).

In the anti-saccade and anti-tapping tests, both APDS patients underperformed controls (anti-saccade performance: P1 = 43\%, C1 = 89\%, P2 = 50\%, C2 = 74\%; anti-tapping performance: $\mathrm{P} 1=31 \%, \mathrm{C} 1=88 \%, \mathrm{P} 2=50 \%, \mathrm{C} 2=83 \%$ ) (Fig. 2a). While patient eye latency was faster when compared to respective controls $(P 1=329 \mathrm{~ms}, \mathrm{C} 1=344 \pm 33 \mathrm{~ms}, \mathrm{P} 2=414$ $\mathrm{ms}, \mathrm{C} 2=490 \pm 23 \mathrm{~ms}$ ), indicative of frontal inhibition deficits (41), P1 hand latency was

144 increased during tapping ( $\mathrm{P} 1=514 \mathrm{~ms}$ vs $\mathrm{C} 1=462 \pm 33 \mathrm{~ms} ; 1.6 \mathrm{SD}$ difference). P2 presented 145 delayed hand execution time (time between screen bar release to target) (P2 = 992ms vs C2 $146=132 \pm 35 \mathrm{~ms} ;>24.5 \mathrm{SD}$ difference) combined with faster hand latency (P2 = $398 \mathrm{~ms}$ vs C2 $147=636 \pm 23 \mathrm{~ms}$ ) (Fig. 2b, d). Together, our data show that P1 presents with movement 148 integration deficits while P2, despite better performance to age-matched controls, exhibits delayed movement execution. requiring both inhibition and memory retrieval (Fig. 1a, b). While performance in the memory- 
152

saccade task was similar for all groups ( $\mathrm{P} 1=75 \%, \mathrm{C} 1=79 \%, \mathrm{P} 2=759 \%, \mathrm{C} 2=85 \%$ ) (Fig. 2a), both patients exhibited delayed eye latency ( $\mathrm{P} 1=483 \mathrm{~ms}, \mathrm{C} 1=406 \pm 17 \mathrm{~ms} ;>4.5 \mathrm{SD}$ difference, P2 = $524 \mathrm{~ms}, \mathrm{C} 2=449 \pm 24 \mathrm{~ms}$; > 3 SD difference) (Fig. 2b). In line with the antitapping task, P1 presented with increased hand latency, compared to controls ( $\mathrm{P} 1=678 \mathrm{~ms}$ vs $\mathrm{C} 1=524 \pm 21 \mathrm{~ms} ;>7 \mathrm{SD}$ difference) whereas P2 exhibited severely delayed hand execution time (P2 = $919 \mathrm{~ms}$ vs C2=146 $\pm 39 \mathrm{~ms}$; > $19.5 \mathrm{SD}$ difference) (Fig. 2e). These results show that, while target location was remembered by both patients, in addition to the aforementioned motor integration deficits, recalling target position was delayed.

\section{$P I 3 K \delta$ is expressed in adult mouse brain}

Our patient data suggested that PIK3CD GOF increased the risk of neuropsychiatric dysfunction, supporting previous reports $(8,9)$. To fully characterize the extent of neurological deficits and establish an animal model to test future pharmacological interventions, we resorted to a heterozygous mouse model of APDS (E1020K knock-in mouse, further referred to as "p1108E1020K mice") (11), to explore the effects of Pik3cd GOF on behaviour.

Prior work in WT mice with a lacZ-p110ס reporter indicated the presence of $p 110 \delta$ in adult brain, predominantly in the cortex and hippocampus (17). Supporting these results, we detected an $110 \mathrm{kDa}$ band in both WT and p1108E1020K brain tissue (Supplementary Fig. 1). p110ס was highly expressed in the spleen, as expected due to abundant B cell populations (42). In the brain, we found lower expression levels of $\mathrm{p} 110 \delta$, primarily detected in the cortex, hippocampus and olfactory bulbs (Supplementary Fig. 1).

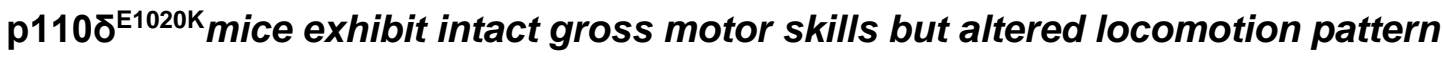

Having confirmed the expression of $\mathrm{PI} 3 \mathrm{~K} \delta$ in the brain, we proceeded with behaviour testing. We first assessed motor performance, which is found to be impaired in a number of patients with neurodevelopmental delay, particularly ASD $(43,44)$. Spontaneous locomotion 
was tested in the open-field arena (Fig. 3a). Both WT and $\mathrm{p} 110 \delta^{\mathrm{E} 1020 \mathrm{~K}}$ mice moved more during the first 10 mins of exploration (Supplementary Fig. 2a), with mean speed and distance travelled across the total 30 mins of testing similar between genotypes (speed: $t(28)=0.5494$, $p=0.59$; distance: $t(28)=1.234, p=0.22)$ (Fig. 3b,c). PI3Kס mutation also did not affect performance on the rotarod test (Fig. 3d) (main effect of genotype, $F(1,28)=0.1789, p=0.68$ ), indicating that $\mathrm{p} 110 \delta^{\mathrm{E} 1020 \mathrm{~K}}$ mice have no gross motor defects.

To investigate fine motor skills, mice were tested with the Erasmus ladder, a fully automated behavioural apparatus that allows detailed analysis and quantification of motor performance and learning in mice (45). p110 $10 \delta^{\mathrm{E} 1020 \mathrm{~K}}$ mice spent significantly less time crossing the ladder on the first two days of testing (Day 1: $U=60, p=0.05$; Day 2: $U=40, p=0.01$ ) (Fig. 3e). This was not prompted by a higher efficiency in crossing the ladder, as the percentage of missteps was similar for each day in both genotypes (main effect of genotype: $F(1,28)=1.786, p=0.19)$ (Supplementary Fig. $2 c)$. We next analysed the locomotion pattern on the ladder (Fig. 3f). Although WT and p110 $10 \delta^{\mathrm{E} 1020 \mathrm{~K}}$ had identical percentages of backsteps $(F(1,28)=2.784, \mathrm{p}=0.11)$ and longsteps $(F(1,28)=0.4735, \mathrm{p}=0.50), \mathrm{p} 110 \delta^{\mathrm{E} 1020 \mathrm{~K}}$ mice displayed a tendency to use a higher percentage of short steps $(F(1,28)=3.469, \mathrm{p}=0.07)$ and used fewer jumps $(F(1,28)=4.112, p=0.05)$ to cross the ladder (Fig. $3 g)$. These pattern changes were independent of weight as this progressed similarly between groups (Supplementary Fig. 3).

Together, these results indicate that PI3Kס GOF mutation has no impact on gross motor function, but contributes to changes in fine locomotor skills that result in the adoption of a different locomotion strategy by mutant mice. This is in line with the findings in our patients, who do not present with gross motor function impairments either, but do present with finemotor movement impairments.

$\mathrm{p} 110 \delta^{\mathrm{E} 1020 \mathrm{~K}}$ mice show altered patterns of repetitive behaviour independent of anxiety-

\section{like measures}



the presence of developmental delays $(47,48)$. To further investigate anxiety-like behaviour in $210 \mathrm{p} 110 \delta^{\mathrm{E} 1020 \mathrm{~K}}$ mutants, we tested mice in the open-field (OF) and elevated-plus maze (EPM) 211 tests.

In the OF, we found no evidence of increased anxiety-like behaviour in $\mathrm{p} 110 \delta^{\mathrm{E} 1020 \mathrm{~K}}$ mice, as both genotypes spent comparable time in the inner and outer areas of the arena (In: $214 U=67, p=0.10$; Out: $U=103, p=0.71)$, as well as in the corners $(U=111, p=97)$ (Fig. 4a,b, 215 Supplementary Fig.2b). There was also no effect of genotype in the EPM regarding the time 216 spent on the different arms of the maze $(F(1,28)=0.10, p=0.75)$ or the number of transitions 217 between arms $(F(1,28)=3.18, p=0.09)(F i g .4 c, d)$. These data indicate that $p 110 \delta^{E 1020 K}$ mice 218 do not exhibit increased anxiety despite their immunological phenotype (11). neurodevelopmental delays (49). Using the marble burying task (Supplementary Fig. 4a,b), we first measured the total area buried by each mouse and found this to be similar between genotypes (area buried: $\mathrm{t}(26)=0.43, \mathrm{p}=0.67$; number of buried marbles: $\mathrm{t}(26)=0.00, p>$ 0.99) (Fig. 4e, Supplementary Fig. 4c). When the location of the buried marbles was mapped, we found that WT mice preferably buried marbles in the bottom right corner and centre, while $\mathrm{p} 110 \delta^{\mathrm{E} 1020 \mathrm{~K}}$ mice favoured areas close to the walls of the arena (Fig. 4f), indicating increased thigmotactic behaviour.

As the previous results suggested the presence of a distinct repetitive behaviour pattern, we further addressed this using the grooming assay. The total time spent grooming was similar between groups $(\mathrm{t}(28)=0.96, \mathrm{p}=0.34)$ (Fig. $4 \mathrm{~g})$, as was the total number of grooming bouts $(\mathrm{t}(28)=1.65, \mathrm{p}=0.11)$ (Fig. $4 \mathrm{~h})$ and latency to initiate grooming behaviour $(t(28)=0.25, p=0.81)$ (Supplementary Fig. $4 d$ ). We found a tendency for the average time interval between grooming bouts to be smaller in $\mathrm{p} 110 \delta^{\mathrm{E} 1020 \mathrm{~K}}$ mice $(\mathrm{t}(28)=1.98, \mathrm{p}=0.06)$ (Fig. $4 i, j)$, further suggesting a difference in behaviour pattern between groups. Indeed, a significant interaction between genotype and short and long grooming bouts (genotype $x$ type of bout: $F(1,28)=5.31, p=0.03)$ revealed that $p 110 \delta^{E 1020 K}$ mice exhibited a higher prevalence of short 
bouts compared to WT, while the opposite was observed for the long bouts (short bouts: $13.29 \%$ in WT vs $19.46 \%$ in p110 ${ }^{\mathrm{E} 1020 \mathrm{~K}}$; long bouts: $86.71 \%$ in WT vs $80.54 \%$ in $\mathrm{p} 110 \delta^{\mathrm{E} 1020 \mathrm{~K}}$ ) (Supplementary Fig. 4e). Furthermore, when the number of grooming bouts was analysed over time, a tendency for increased bout number over time was seen in $\mathrm{p} 110 \delta^{\mathrm{E} 1020 \mathrm{~K}}$ mice towards the end of the assay (genotype $x$ time: $F(9,251)=2.15, p=0.03$ ) (Fig. 4k, bottom curve). A significant time $x$ genotype interaction was also found for the 3 minute-binned time spent grooming $(F(9,273)=3.51, p=0.0004)$ (Fig. 4k, top curve), further supporting the presence of an altered grooming pattern in $\mathrm{p} 110 \delta^{\mathrm{E} 1020 \mathrm{~K}}$ mice. Taken together, these data

244 indicate that, despite the absence of increased anxiety-like behaviour, $\mathrm{p} 110 \delta^{\mathrm{E} 1020 \mathrm{~K}}$ mice present with subtle alterations in the pattern of repetitive behaviour.

\section{p110 ${ }^{E 1020 K}$ mice exhibit changes in associative response} patients $(7,9)$, including $\mathrm{P} 1$, we investigated associative and spatial learning in the $\mathrm{p} 110 \delta^{\mathrm{E} 1020 \mathrm{~K}}$ mice. task, two stimuli are presented. Initially, a light turns on inside the goal box. Next, an air stream encourages the mouse to enter the ladder (45) (Fig. 5a). Considering the exit frequency for each stimulus, we found that both genotypes responded similarly to stimuli in the first sessions of the task. For sessions 3 and $5, \mathrm{p} 110 \delta^{\mathrm{E} 1020 \mathrm{~K}}$ mice left the goal box less frequently with the air stimulus than WT (session $3: U=61, p=0.03$; session 5 : $U=55.5, p=0.02$ ) (Fig. $5 b$ ), while increasing box exits after light presentation in later sessions (session $4: U=63.5, p=$ 0.07; session 5: $U=63.5, p=0.04$ ) (Fig. $5 c, e$ ). Increased light exit frequency could be representative of increased readiness or impulsivity to leave the box, interrupting the prestimulus waiting period. From testing days 1 to 4 , both genotypes left the box before cue presentation with similar frequencies (Fig. 5d). On day 5, this frequency was increased in 
between leaving before cue and the light/air exit ratio (WT: $\rho=0.49, p<0.0001 ; p 110 \delta^{\mathrm{E} 1020 \mathrm{~K}}$ : $\rho=0.63, p<0.0001)$. Least squares fitting demonstrated that the response of the two genotypes to the stimuli was significantly different $(F(2,139)=3.906, p=0.02$; WT: $y=$ $\left.4.9 x+3.8 ; p 110 \delta^{E 1020 K}: y=2.3 x+4.5\right)$ (Fig. 5f). used to study repetitive behaviour and cognitive flexibility in ASD-mouse models (50-52). Similar to the previous OF and Rotarod results, we found no evidence of motor dysfunction, with both genotypes swimming similar distances and at comparable speeds during the 272 habituation phase (distance: $U=67, p=0.22$; speed: $U=77, p=0.23$ ) (Supplementary Fig. $2735 a, b)$. During the acquisition and test phases, both WT and $\mathrm{p} 110 \delta^{\mathrm{E} 1020 \mathrm{~K}}$ mice learned the 274 platform location, and there was no difference in the number of correct arm choices made by each genotype (Fig. $5 \mathrm{i}, \mathrm{j})$. When the location of the platform was reversed, p110 $10 \delta^{\mathrm{E} 1020 \mathrm{~K}}$ mice presented with a lower cumulative median of correct choices per trial, taking longer to perform the task correctly (Fig. 5k). No significant differences were found in the total number of correct choices per session (Fig. 5l). Similar results were obtained regarding the reversal II phase

279 (Supplementary Fig. 5d,e). However, in this phase, errors in platform arm choice were only performed by $\mathrm{p} 110 \delta^{\mathrm{E} 1020 \mathrm{~K}}$ mice $(\mathrm{U}=45.5, \mathrm{p}=0.01)$ (Supplementary Fig. $\left.5 \mathrm{e}\right)$. Taken together, these results indicate that $\mathrm{p} 110 \delta^{\mathrm{E} 1020 \mathrm{~K}}$ mice present with mild deficits in paired-stimulus learning and reversal learning.

\section{$p 110 \delta^{E 1020 K}$ mice display intact social interaction behaviour}

Atypical development of social skills and interactions is a common component of neuropsychiatric conditions, particularly of those with ASD comorbidity $(53,54)$. Therefore, we sought to evaluate the performance of $\mathrm{p} 110 \delta^{\mathrm{E} 1020 \mathrm{~K}}$ mice in a social interaction paradigm (55). was presented, both genotypes displayed a similar ambulatory behaviour across all chambers $(F(1,28)=0.5376, p=0.47)($ Supplementary Fig. $6 a, c) \cdot p 110 \delta^{\mathrm{E} 1020 \mathrm{~K}}$ mice displayed slightly 
altered exploratory behaviour, with a tendency for centre crossing avoidance (genotype $\mathrm{x}$ chamber: $F(2,55)=2.988, p=0.06$; WT mean centre transitions $=46.57$ vs $p 110 \delta^{\mathrm{E} 1020 \mathrm{~K}}$ mean centre transitions $=38.40$ ) (Supplementary Fig. 6d). During the test phase, a novel mouse was introduced to the arena (Fig. 6a). Both WT and p110 $\delta^{\mathrm{E} 1020 \mathrm{~K}}$ mice spent more time in the chamber where the novel mouse was located (main effect of chamber: $F(1.911,79.30)=87.71$, $p<0.0001$; main effect of genotype: $F(1,83)=0.0006, p=0.98)$ (Fig. 6b), increasing the time spent in this chamber compared to their correspondent baseline values (main effect of phase: $F(1,28)=98.74, p<0.0001$; main effect of genotype: $F(1,28)=0.2441, p=0.63)$ (Fig. $6 c$ )

Similar to what was found for the baseline exploration period, the avoidance of central area crossings in $\mathrm{p} 110 \delta^{\mathrm{E} 1020 \mathrm{~K}}$ mice persisted in the test phase (genotype $x$ chamber: $F(2,54)=$ $5.423, p=0.01 ;$ WT mean centre transitions $=27.21 \mathrm{vs} \mathrm{p} 110 \delta^{\mathrm{E} 1020 \mathrm{~K}}$ mean centre transitions $=$ 23.64) (Supplementary Fig. 6e).

Focusing on the region of interest defined around the empty cup and the cup with the novel mouse, both genotypes demonstrated a comparable preference for interacting with the cup where the social stimulus was located $(t(28)=0.99, p=0.33)$, spending approximately twice the time exploring this cup compared to the empty cup (Fig. 6d,e). This preference for social cup exploration was also accompanied by an increased number of transitions into the novel mouse cup area (main effect of cup: $F(1,28)=29.04, p<0.0001$ ) (Fig. 6f, g). For both genotypes, the time spent exploring the novel social stimulus progressively decreased over 311 the course of the task (main effect of time: $F(1.328,118.8)=5.714, p=0.0002$; main effect of 312 genotype: $F(1,28)=0.3303, p=0.57$ ) (Supplementary Fig. $6 b$ ). Finally, when social 313 investigation preference was analysed, $\mathrm{p} 110 \delta^{\mathrm{E} 1020 \mathrm{~K}}$ mice exhibited a tendency to spend a

314 lower proportion of their time in the novel mouse chamber in the proximity of the cup, although 315 this did not reach the statistical significance threshold $(t(28)=1.877, p=0.07)$ (Fig.6h). 316 Altogether, these data indicate that, despite a slight centre avoidance phenotype, p110 mice prefer the social stimulus over the asocial one, exhibiting an unaffected social phenotype. 
319 Motor, learning and repetitive behaviours best discriminate WT and $p 110 \delta^{E 1020 K}$ mouse populations

321

The analysis of independent readouts for each behaviour revealed a number of discrete changes in the behavioural pattern of $\mathrm{p} 110 \delta^{\mathrm{E} 1020 \mathrm{~K}}$ mice. Nonetheless, behaviour is a dynamic process where small stereotyped modules are often grouped or combined into larger representations that underlie each individual's phenotype $(56,57)$. To better understand the most important contributors to the phenotype of $\mathrm{p} 110 \delta^{\mathrm{E} 1020 \mathrm{~K}}$ mice, we performed linear discriminant analysis (LDA) on all behavioural variables measured $(58,59)$. This type of analysis allows for encompassing individual differences across individuals and captures stable traits best separating the genotypes across many tests (59). We then selected the first two dimensions, LD1 and LD2 (Fig. 7a), and plotted the 10 best contributing components of each discriminant, as these are the variables that give the most information on group separation (Fig. 7b).

LDA of the behavioural data classified individual points into 2 non-overlapping classes,

334 identifying the two genotypes. The 2 best LDs represent $68.1 \%$ of data variation, with LD1, which explains $41.7 \%$ of total data variation, creating a maximal separation between classes. Focusing on the greatest weights, motor and learning related variables (time on ladder and light to air ratio, respectively) contribute the most for group classification. The third feature, total grooming time, with an absolute contribution of $8.5 \%$, indicates that additional group separation is achieved by the inclusion of repetitive behaviours in this discriminant. Further separation of the data along the vertical axis is provided by LD2, albeit with lower contributions (26.4\%). This discriminant represents parameters predominantly influenced by locomotionderived features. These include total distance travelled and transitions made during the test phase of the SI, and total distance travelled during the EPM. Altogether, these results indicate that LDA compiles and captures behavioural alterations in locomotor performance, learning and repetitive behaviours between WT and $\mathrm{p} 110 \delta^{\mathrm{E} 1020 \mathrm{~K}}$ mice, supporting the previously identified univariate analysis findings. 


\section{Discussion}

The study of the immune system in the regulation of neurodevelopment and in shaping subsequent behaviour is a rapidly emerging field, involving crosstalk in immunoneuropsychiatry and new integrative therapeutic approaches (60-62). In this work, we investigated neurologically-relevant behavioural features in APDS, a rare PID, using both patient data and a murine model. To our knowledge, this is the first study of APDS which specifically focuses on its behavioural component.

APDS patients exhibited changes in visuomotor responses, with P1 presenting with motor integration deficits, while both patients displayed decreased memory recall capacity. Additionally, P1 was also formally diagnosed with ASD, strengthening on previous more general reports describing neurodevelopmental delay as a comorbidity of APDS patients $(8,9,13,63)$. In the $\mathrm{p} 110 \delta^{\mathrm{E} 1020 \mathrm{~K}}$ murine model, we detected more subtle phenotypic alterations. GOF mice presented with altered patterns of locomotion and repetitive behaviours, features reminiscent of symptoms found in individuals with ASD $(49,64)$.

While our data supported a role of PIK3CD GOF on behaviour, the precise function of PI3Kס in the brain remains elusive. In mice, $\mathrm{p} 110 \delta$ has been found in brain and spinal cord, and proposed to have a role in neuronal morphology $(12,17,22,23)$. Although the expression pattern of human PIK3CD follows a similar distribution as in mice (Allen Human Brain Atlas (2010)), reports of its non-immunological functions are scarce, with only a few studies implicating this isoform in schizophrenia and autism $(18,24,65)$. The presence of behavioural deficits in adult mice combined with the low PI3Kס expression in the brain, suggests that this isoform might have a predominant function during brain development rather than adulthood. Consistent with this hypothesis, recent studies found more PIK3CD transcripts in human foetal brain than in adult samples (18) and distributed expression of PIK3CD in the developing mouse brain (66). Combined with the fact that PI3Kס lies upstream of the mTOR pathway, a 373 signalling hub that is highly active during brain development and often found to be 
375 PIK3CD plays a still unexplored role in the modulation of brain development, adding to the 376 growing body of evidence pointing to a critical period for ASD development $(52,69)$. number of studies has now suggested a link between neurodevelopmental and immunological dysregulation. For example, in rodents, externally triggering a maternal immune response during pregnancy induces behavioural alterations in adult offspring. These include reduced cognitive flexibility and decreased social exploration, traits of an ASD-like phenotype (70-72). In humans, increased odds of neonatal infections were reported for children with ASD (73). Additionally, viral or bacterial infections during pregnancy were associated with an increased likelihood of ASD diagnosis $(74,75)$, whereas increased ASD symptom severity was found in children with a maternal history of chronic immune activation (76). In APDS, family history of immunodeficiency is also estimated in $39 \%$ of patients (7), thus suggesting that PID might be an important predictor of neuropsychiatric load. Strengthening the hypothesis of an immunological-behavioural phenotype relationship is the presentation of the described patients, with P1 displaying increased immunodeficiency and visuomotor impairments, in addition to an ASD diagnosis, when compared to P2. Overall, the indirect links between immune and neuropsychiatric dysfunction indicates that immunological burden may be an important predictor for the development of atypical behaviour, not only in APDS, but also in other PID $(77,78)$.

Interestingly, in individuals with ASD and ASD animal models, altered microbiota has been reported, with studies describing lower diversity profiles of colonizing microbiota in these groups (79-82). Highlighting a putative ASD-microbiota relationship, a recent follow-up study on microbial transfer therapy reported that ASD participants still scored $47 \%$ lower than baseline on the Childhood Autism Rating Scale and 35\% lower on the Aberrant Behavior 400 Checklist two years after trial conclusion, suggesting that microbiota regularization may 401 improve autism-related scores on a longer term (83). Importantly, preclinical evidence 402 suggests that $\mathrm{PI} 3 \mathrm{~K} \delta$ may play a role in microbiota regulation. Indeed, Pik3cdE1020K/+ mice were 
shown to exhibit increased antibody production and reactivity against autologous commensal bacteria (84), whereas mice with PI3Kס loss-of-function develop colitis due to pathogenic T cell responses and altered IL-10 and IL-12p40 production $(85,86)$. Thus, although human data are essential to further explore these hypotheses, given that $22 \%$ to $29 \%$ of APDS patients present with enteropathy (7), it would be important for future PI3Kס studies to consider its possible role in microbiota homeostasis.

The interplay between the immune system and the brain is a current topic of rapid 410 scientific discovery $(87,88)$. Here, we show that a heterozygous mouse model of APDS 411 displays mild behavioural alterations in addition to its immunological phenotype. ADPS 412 patients showed high levels of heterogeneity when it came to behavioural and immunological 413 symptoms. However, both P1 and P2 presented with sensorimotor deficits, a feature captured 414 by the mouse model. Notably, the severity of the symptoms between P1 and P2 was reflected 415 in the performance during the visuomotor tests. This is of interest to the APDS community, 416 because such tests have previously been shown to accurately capture the features of early 417 stage Alzheimer's disease (89), correlate with cognitive impairments in Parkinson's disease 418 (90), and serve as a tool to monitor the progression of both conditions (91). Further, due to 419 their non-invasive nature, such tests are suitable to use even in very young children (92). In 420 the future, we aim to further explore the correlation between immune system impairments, behavioural deficits and the outcome of the visuomotor deficits, on a larger APDS patient cohort, assessing the potential benefits of including this type of test batteries in the diagnostic pathway.

In addition to reinforcing the need for a multidisciplinary team assessing APDS patients, this study highlights the importance of increased monitoring of immunodeficient patients for the presence of neuropsychiatric comorbidities and describes a set of non-invasive tools that allow for such assessment. Additional studies on the function of $\mathrm{PI} 3 \mathrm{~K} \delta$ in the brain will be fundamental to understand its specific role in neurodevelopment and deepen our knowledge of the interactions between immunological burden and neuropsychiatric load. 


\section{Methods}

\section{Patients}

433 We describe two APDS patients (Table 1,2). P1 is regularly followed (by VD) at the Primary 434 Immunodeficiency Center of the Department of Internal Medicine, Division of Clinical 435 Immunology, Erasmus MC (Rotterdam, The Netherlands); P2 is currently under treatment (by 436 SMA) at the outpatient Department of Infectious Diseases of Leiden University Medical Center 437 (Leiden, The Netherlands). Psychiatric assessment was performed (by NB) at the Erasmus $438 \mathrm{MC}$ and included the autism-spectrum quotient (27). Additional clinical history and data were 439 obtained from medical notes (by OM, VD and SMA).

\section{Visuomotor coordination and memory assessment}

442 An eye-hand coordination measurement setup was used to quantify the interactions between 443 visual, ocular motor, and manual motor systems in both spatial and temporal domains. It 444 consisted of a 21.5" touchscreen monitor (Wacom DTH-2242, Wacom Corporation, Japan), a 445 remote infrared and screen-based eye-tracker (Tobii Pro X3, Tobii Corporation, Sweden) and 446 a wired keyboard. The eye-tracker, positioned below the touchscreen, recorded eye 447 movements at $120 \mathrm{~Hz}$ and was connected via an external processing unit to a laptop (DELL 448 Latitude 5590, Dell Technologies, Texas, United States) with an Intel Core i5-8350U processor, 256 GB SSD, and 16 GB internal RAM to warrant optimal performance and data quality (Pro, 2017). Eye movements with a speed $>50 \%$ s were considered saccades. Manual responses were captured by sampling alternating presses and releases of the index finger

452 from the dominant hand, between keyboard and touchscreen. After a short general instruction, each subject was instructed to sit straight in front of the touchscreen. Eye positions were calibrated at approximately $65 \mathrm{~cm}$ from the touchscreen using a standard calibration procedure. Next, 7 tasks, 3 eye tasks and 4 eye-hand tasks (Fig. 1), were presented on the touch screen in a fixed order (see below). Standard verbal instructions were given prior to each task and each subject was allowed a maximum of three practice trials. These instructions were also written on the screen (in Dutch). The starting position at each trial was fixating a 
central white dot and, in case of eye-hand tasks, also touching a blue bar at the bottom of the screen with the index finger for 2 seconds. The following 16 trials within each task had to be executed as fast and as accurately as possible. The following tasks were performed:

1. Pro-Saccade and 2. Pro-tapping: The subject had to fixate (pro-saccade) or touch (protapping) a randomly appearing peripheral dot.

464 3. Anti-Saccade and 4. Anti-Tapping: The participant had to make an eye movement (antisaccade) or an eye and hand movement (anti-tapping) in the opposite direction of a randomly appearing peripheral dot, at either 5, 10, 15 or 20 degrees of the horizontal direction.

5. Memory-Saccade and 6. Memory-Tapping: While fixating the central dot, a peripheral dot appeared for $50 \mathrm{~ms}$ at a random position. The subject had to fixate (memory-saccade) or touch (memory-tapping) the remembered peripheral dot location after the central dot disappeared. along the trajectory, the ball became invisible and the subject had to touch the basket in which the ball would have fallen.

473

\section{$474 \quad$ Mice procedures}

475 Thirty 10 to 13 week-old wild-type $(n=15$ WT) and heterozygous p110 $\mathrm{E}$ E1020K $(n=15$ $\mathrm{p} 110 \delta^{\mathrm{E} 1020 \mathrm{~K}}$ ) male mice were kindly provided by Dr. Klaus Okkenhaug (University of

477 Cambridge, United Kingdom). These mice harbour an E1020K knock-in mutation in the Pik3cd gene expressed in all cells (11). Following arrival to the Erasmus MC, mice were acclimated

479 to the facilities for two weeks. Mice were group-housed (3 to 4 mice per cage, mixed genotypes 480 in the same cage), provided with food and water ad libitum and kept on a regular $12 \mathrm{~h}$ light/dark 481 cycle. After this acclimatization time, mice were handled by the experimenters for three days 482 prior to experiment initiation. Before each experiment, mice were weighed (Supplementary 483 Figure 3) and habituated to the testing room for at least $1 \mathrm{~h}$. Experimenters were blinded to the genotype of each mouse. 
485 When all behavioural experiments were completed, brain tissue was collected. Mice were

486 injected with an overdose of pentobarbital, transcardially perfused with $0,9 \% \mathrm{NaCl}$, and the

487 brain dissected. Tissue was flash frozen and kept at $-80^{\circ} \mathrm{C}$ until used.

488

489 Genotyping

490 Mice were genotyped by amplifying the Pik3cd locus from mouse ear DNA using the forward

491 E1020KrecF1 (5'-TCCTCATGGCATCCTTGTCC-3') primer and the reverse E1020Kflox-

492 recR11 (5'-TGGTCCACCCGTTGACTCAA-3') primer by PCR. PCR products were run on a

$4931 \%$ agarose gel. The wild-type allele resulted in a $381 \mathrm{bp}$ band and the recombined $\mathrm{p} 110 \delta^{\mathrm{E} 1020 \mathrm{~K}}$

494 allele resulted in a 436 bp band.

495

496 Behavioural testing

497 All mouse behavioural tasks, except the Erasmus ladder, Rotarod and Y-maze, were

498 performed in a behavioural box. This consisted of a $130 \times 80 \times 80 \mathrm{~cm}$ wooden box with a door,

499 lined with $6 \mathrm{~mm}$ high-pressure laminate and foam, with a $10 \mathrm{~mm}$ Perspex® shelf and

500 standardized white and infrared lights. Metal grooves on the Perspex ${ }^{\circledR}$ shelf assured constant

501 positioning of the testing arenas across experiments. All experiments were recorded with a

502 fixed camera (acA 1300-600gm, Basler AG) positioned above the arenas and operated

503 through the open-source software Bonsai (https://bonsai-rx.org). A frame rate of 25 frames

504 per second (fps) was used for all tests, except for the Grooming assay and the Y-maze, where

$50530 \mathrm{fps}$ were used. After behavioural testing, video recordings were uploaded to the open-

506 source software OptiMouse (93), where each mouse was tracked and measures such as

507 speed and time spent in regions of interest (ROls) were extracted. Behavioural tasks were

508 performed as previously described and in the following order: 1) Erasmus ladder (Noldus,

509 Wageningen, the Netherlands) (45); 2) Social interaction (52); 3) Grooming (94); 4) Elevated-

510 plus maze (52); 5) Open-field (95); 6) Marble burying (96); 7) water Y-maze (52); 8) Rotarod

511 (97). The order of the assays was the same for all mice. For detailed information on each

512 assay see Supplemental materials. 


\section{Western blot}

514 Brain tissue was lysed and homogenized in RIPA Lysis and Extraction Buffer (Thermo

515 Scientific ${ }^{\top \mathrm{M}}$ ), supplemented with Halt ${ }^{\mathrm{TM}}$ Protease and Phosphatase Inhibitor Cocktail (Thermo

516 Scientific $\left.^{\mathrm{TM}}\right)$. Protein concentration was determined with Pierce ${ }^{\mathrm{TM}}$ BCA Protein Assay Kit

517 (Thermo Scientific ${ }^{\mathrm{TM}}$ ). Protein lysates were mixed with $4 \mathrm{X}$ Laemmli Sample Buffer,

518 supplemented with 2-mercaptoethanol (Bio-Rad Laboratories B.V.) and incubated at $100^{\circ} \mathrm{C}$

519 for $6 \mathrm{~min}$. Eighty $\mu \mathrm{g}$ (brain and spleen tissue of WT and $\mathrm{p} 110 \delta^{\mathrm{E} 1020 \mathrm{~K}}$ mice) or $40 \mu \mathrm{g}$

520 (splenocytes of WT and Pik3cd ${ }^{-/-}$mice) of lysate were loaded onto 4-15\% Mini-PROTEAN ${ }^{\circledR}$

521 TGX $^{\mathrm{TM}}$ Precast Protein Gels (Bio-Rad Laboratories B.V.). Transfer was performed onto

522 Immobilon ${ }^{\circledR}$-P PVDF Membranes (Merck KGaA). Membranes were blocked with 5\% BSA

523 (Merck KGaA) in TBS (Merck KGaA) for $1 \mathrm{~h}$ and subsequently incubated with anti-PI3K p110ठ

524 (D1Q7R) Rabbit mAb (1:1.000, \#34050, Cell Signaling Technology, B.V.) in 5\% BSA-TBS with

$5250,1 \%$ Tween 20 (TBS-T) (Merck KGaA) overnight at $4^{\circ} \mathrm{C}$. Membranes were washed three

526 times with TBS-T and incubated with IRDye ${ }^{\circledR}$ 800CW Goat anti-Rabbit lgG $(1: 10.000, H+L$;

527 LI-COR Biosciences - $\mathrm{GmbH}$ ) in 5\%-BSA-TBS-T for $1 \mathrm{~h}$ at room temperature. Membranes

528 were washed three times with TBS-T and imaged in an Odyssey ${ }^{\circledR}$ CLx Imaging System.

529 Afterwards, membranes were incubated with GAPDH (D16H11) XP ${ }^{\circledR}$ Rabbit mAb (1:1.000

530 dilution, \#5174, Cell Signaling Technology, B.V.) in 5\% BSA-TBS-T overnight at $4^{\circ} \mathrm{C}$.

531 Membranes were washed three times with TBS-T and incubated with IRDye ${ }^{\circledR} 800 \mathrm{CW}$ Goat anti-Rabbit IgG (1:10.000, H + L; LI-COR Biosciences - GmbH) in 5\%-BSA-TBS-T for $1 \mathrm{~h}$ at

533 room temperature. Membranes were washed three times with TBS-T and imaged in an

534 Odyssey ${ }^{\circledR}$ CLx Imaging System. Western blots were visualized with Image Studio Lite ${ }^{\mathrm{TM}}$ software (LI-COR Biosciences - GmbH).

536

\section{Linear discriminant analysis}

538 For multivariate analysis, linear discriminant analysis (LDA) was performed to identify the

539 behavioural features that best separate WT and $p 110 \delta^{\mathrm{E} 1020 \mathrm{~K}}$ genotypes $(58,98)$. All variables

540 were initially considered for class separation (see pre-processing steps below). Variables that 
541 consisted of multiple data points, measured over several sessions (e.g. rotarod data, acquired

542 over the course of 5 days), were reduced to a single value variable by calculating the slope

543 across data points, as this can be interpreted as a learning curve of an animal for a given

544 variable. After pre-processing and validation, LDA was performed with a custom written code.

545 The outcome from the LDA was plotted as LD1 vs LD2, with the contribution of the 10 best variables per LD. All code used to perform the pre-processing steps, validation and LDA is available at https://github.com/BaduraLab/LDA_analysis_2 classes.

548

549 Pre-processing

550 Before conducting the LDA, data were pre-processed to comply with the normality assumption by calculating z-scores (98). Z-scores were inspected for every variable and compared with a standard normal distribution. Due to its highly skewed distribution, "Y-maze: reverse II" data were excluded from further analysis. Class approximation of a normal distribution was also assessed by visualising and comparing the z-scored data with a standard normal distribution. Additionally, data points that exceeded 3 scaled median absolute deviations from the median (isoutlier function in Matlab) of the corresponding class per variable, were considered outliers and excluded from further analysis. Excluded outliers were interpolated with the mean of their corresponding class per variable (mean interpolation) $(98,99)$.

Next, a correlation matrix with all tested behaviours was generated (Supplementary Fig. 7a) to exclude strongly correlated variables. Inspection of the matrix identified speed related variables as strongly correlated $(r \geq 0.86)$ with measures of total distance of the corresponding experiment. Therefore, speed variables were excluded in this step, while distance variables were kept for further analysis, which resulted in 31 behavioural measures included in the LDA.

564 Finally, we applied the Moore-Pseudo Inverse method to allow inclusion of all variables in the analysis by approximating the inverse of the within variance matrix (100). This last step was necessary because one of LDA's criteria is that the total number of variables analysed must be lower or equal to the total number of samples minus the number of classes (98). 
LDA validation

570 To validate the results of the LDA, data was shuffled 200.000 by randomizing data labelling.

571 This number was chosen by shuffling a random dataset $N$ times until an error margin of under

$5725 \%$ was achieved, based on the concept of a Monte Carlo simulation (101). With each shuffle,

573 the individual data points were randomly assigned to two equally sized classes. While dominant features can still appear dominant while shuffling, provided that these variables are

575 actually not dependent, exactly equal combinations of contributions were predicted to be low and therefore different from the final LDA results. After shuffling, the first LD1 variable, Time on ladder (EL), appeared $0.21 \%$ of the times in $1^{\text {st }}$ place, the second variable, Light/air ratio $(E L)$, was above $18.73 \%$ of the times in $2^{\text {nd }}$ place, and the third variable, Total time $(G)$, appeared $1.81 \%$ of the times in $3^{\text {rd }}$ place (Supplementary Fig. $7 \mathrm{~b}$ ). The rank sum of the first two features appeared $0.013 \%$ of times and the rank sum of the first three appeared $0 \%$ of times.

582

\section{Statistics}

584 For the analysis of patient visuomotor data, a customized MATLAB script (Mathworks, Natick, MA, USA) was used to visually inspect and analyze all the measured trials. Three outcome measures were considered: 1) Performance - percentage of correctly performed trials; 2) Eye Latency (EL) - time between the presentation of a peripheral stimulus and initiation of the primary saccadic eye movement; 3) Hand Latency $(\mathrm{HL})$ - time between the presentation of a peripheral stimulus and the release of the index finger from the keyboard. The control groups,

$590 \mathrm{C} 1$ and $\mathrm{C} 2$, were age-matched to patients $\mathrm{P} 1$ and P2, respectively. The age and number of control patients is presented in Table 3.

592 For mouse behavioural data, statistical analysis involving hypothesis testing and group comparison was performed with the Graphpad Prism 8 software. Data sets were first tested for the presence of significant outliers using the Grubbs test, and then for the assumption of normality, using the Shapiro-Wilk test and Q-Q plots. When normality was followed, WT and 
597 ANOVA, depending on the parameters analysed. When data violated the assumption of

598 normality, a two-tailed Mann-Whitney test was performed instead. A mixed effects model was

599 used in place of repeated measures ANOVA when data points were missing or excluded

600 (outliers). The statistical significance threshold was set at $p \leq 0.05$. For the analysis of 601 automatically tracked behaviour, body position values were used, except for the "near cup" 602 parameters of the social interaction task. In this case, the nose position was extracted to more 603 accurately represent the interaction between test and novel mice (sniffing the novel mouse).

604

\section{Study approval}

606 Patient P1 had previously been recruited for a longitudinal, multi-center, cohort study on the 607 causes and clinical manifestations of PID. For this study, approval of the Medical Ethics 608 Committee of the Erasmus University Medical Center Rotterdam had been obtained (MEC 609 2013-026). Written informed consent was obtained from patients P1 and P2 according to the 610 Declaration of Helsinki.

611 All experimental animal procedures were approved a priori by an independent animal ethical

612 committee (DEC-Consult, Soest, The Netherlands), as required by Dutch law and conform to 613 the relevant institutional regulations of the Erasmus MC and Dutch legislation on animal 614 experimentation.

615

616

617

618

619

620

621

622

623

624 


\section{Author contributions}

626 IS, AB, VASHD and JJMP designed and supervised the study. AB, KO, VASHD, JJMP 627 provided resources and acquired funding. VASHD, ORM, SMA and NJMB identified patients 628 and performed clinical diagnosis. IIF, JJMP and AB performed the visuomotor experiments.

629 IS and LW performed mouse experiments. FMPK and HI performed in vitro experiments. IS,

630 IIF, LW and CVDZ performed data analysis. IS performed statistical analysis and prepared

631 figures. IS, AB, VASHD and JJMP wrote the first draft. All authors edited the manuscript.

632 IS and ORM share first authorship. ORM and VASHD provided the clinical characterisation of

$633 \mathrm{P} 1$ and P2, whereas IS performed all mouse experiments and coordinated visuomotor data 634 collection and analysis. Because IS drafted the paper, they are listed first.

635

636

637

638

639

640

641

642

643

644

645

646

647

648

649

650

651

652 


\section{Acknowledgements}

654 We thank Peter Katsikis for providing splenocytes of WT and Pik3cd ${ }^{/-}$animals; Roxanne ter 655 Haar and Elize Haasdijk for the biotechnical assistance; and Chris de Zeeuw for helpful 656 comments and histological reagents. This work has been funded by the Stichting Sophia

657 Kinderziekenhuis Fonds (grant no. S15-07 Genes and Immunity in SCID- F.M.P.K.) and the 658 Dutch Research Council (NWO, ZonMw) Talent Programme Vidi (A.B.)

659

660

661

662

663

664

665

666

667

668

669

670

671

672

673

674

675

676

677

678

679

680 


\section{References}

682 1. Gruber, C. \& Bogunovic, D. Incomplete penetrance in primary immunodeficiency: a 683 skeleton in the closet. Hum. Genet. 139, 745-757 (2020).

684 2. Thaventhiran, J. E. D. et al. Whole-genome sequencing of a sporadic primary 685 immunodeficiency cohort. Nature (2020). doi:10.1038/s41586-020-2265-1

3. Amaya-Uribe, L., Rojas, M., Azizi, G., Anaya, J.-M. \& Gershwin, M. E. Primary immunodeficiency and autoimmunity: A comprehensive review. J. Autoimmun. 99, 52 72 (2019).

4. Bethune, C. et al. British Society for Immunology/United Kingdom Primary Immunodeficiency Network consensus statement on managing non-infectious complications of common variable immunodeficiency disorders. Clin. Exp. Immunol.

692 196, 328-335 (2019).

5. Odnoletkova, I. et al. The burden of common variable immunodeficiency disorders: a retrospective analysis of the European Society for Immunodeficiency (ESID) registry data. Orphanet J. Rare Dis. 13, 201 (2018).

6. Abolhassani, H. et al. Clinical, immunologic, and genetic spectrum of 696 patients with combined immunodeficiency. J. Allergy Clin. Immunol. 141, 1450-1458 (2018).

7. Jamee, M. et al. Clinical, Immunological, and Genetic Features in Patients with Activated PI3Kס Syndrome (APDS): a Systematic Review. Clin. Rev. Allergy Immunol. (2019). doi:10.1007/s12016-019-08738-9

8. Coulter, T. I. et al. Clinical spectrum and features of activated phosphoinositide 3-kinase

9. Elkaim, E. et al. Clinical and immunologic phenotype associated with activated phosphoinositide 3-kinase $\delta$ syndrome 2: A cohort study. J. Allergy Clin. Immunol. 138, 210-218.e9 (2016).

10. Dornan, G. L. et al. Conformational disruption of PI3Kס regulation by immunodeficiency mutations in PIK3CD and PIK3R1. Proc. Natl. Acad. Sci. U. S. A. 114, 1982-1987 
(2017).

710

711

712

713

714

715

716

717

718

719

720

721

722

723

724

725

726

727

728

729

730

731

732

733

734

735

736

11. Stark, A.-K. et al. PI3Kס hyper-activation promotes development of B cells that exacerbate Streptococcus pneumoniae infection in an antibody-independent manner. Nat. Commun. 9, 3174 (2018).

12. Nieuwenhuis, B. et al. PI 3-kinase delta enhances axonal PIP3 to support axon regeneration in the adult CNS. EMBO Mol. Med. e11674 (2020).

13. Wang, Y. et al. Report of a Chinese Cohort with Activated Phosphoinositide 3-Kinase $\delta$ Syndrome. J. Clin. Immunol. 38, 854-863 (2018).

14. Thauland, T. J., Pellerin, L., Ohgami, R. S., Bacchetta, R. \& Butte, M. J. Case Study: Mechanism for Increased Follicular Helper T Cell Development in Activated PI3K Delta Syndrome. Front. Immunol. 10, 753 (2019).

15. Wentink, M. et al. Genetic defects in PI3Kס affect B-cell differentiation and maturation leading to hypogammaglobulineamia and recurrent infections. Clin. Immunol. 176, 7786 (2017).

16. Chantry, D. et al. p110delta, a novel phosphatidylinositol 3-kinase catalytic subunit that associates with p85 and is expressed predominantly in leukocytes. J. Biol. Chem. 272, $19236-19241$ (1997).

17. Eickholt, B. J. et al. Control of axonal growth and regeneration of sensory neurons by the p110delta PI 3-kinase. PLoS One 2, e869 (2007).

18. Hood, V. L., Berger, R., Freedman, R. \& Law, A. J. Transcription of PIK3CD in human brain and schizophrenia: regulation by proinflammatory cytokines. Hum. Mol. Genet. 28, 3188-3198 (2019)

19. Tee, A. R., Sampson, J. R., Pal, D. K. \& Bateman, J. M. The role of mTOR signalling in neurogenesis, insights from tuberous sclerosis complex. Semin. Cell Dev. Biol. 52, $12-$ 20 (2016).

20. Jossin, Y. \& Goffinet, A. M. Reelin signals through phosphatidylinositol 3-kinase and Akt to control cortical development and through mTor to regulate dendritic growth. Mol. Cell. Biol. 27, 7113-7124 (2007). 
21. Costa-Mattioli, M. \& Monteggia, L. M. mTOR complexes in neurodevelopmental and neuropsychiatric disorders. Nat. Neurosci. 16, 1537-1543 (2013).

22. Hood, V. L., Paterson, C. \& Law, A. J. PI3Kinase-p110ס Overexpression Impairs Dendritic Morphogenesis and Increases Dendritic Spine Density. Front. Mol. Neurosci. 13, 29 (2020).

23. Schmidt, J. T., Mariconda, L., Morillo, F. \& Apraku, E. A role for the polarity complex and PI3 kinase in branch formation within retinotectal arbors of zebrafish. Dev. Neurobiol. 74, 591-601 (2014).

24. Poopal, A. C., Schroeder, L. M., Horn, P. S., Bassell, G. J. \& Gross, C. Increased expression of the PI3K catalytic subunit $\mathrm{p} 110 \delta$ underlies elevated S6 phosphorylation and protein synthesis in an individual with autism from a multiplex family. Mol. Autism 7, $3(2016)$.

25. Angulo, I. et al. Phosphoinositide 3-kinase $\delta$ gene mutation predisposes to respiratory infection and airway damage. Science 342, 866-871 (2013).

26. Nunes-Santos, C. J., Uzel, G. \& Rosenzweig, S. D. PI3K pathway defects leading to immunodeficiency and immune dysregulation. J. Allergy Clin. Immunol. 143, 1676-1687 (2019).

27. Baron-Cohen, S., Wheelwright, S., Skinner, R., Martin, J. \& Clubley, E. The autismspectrum quotient (AQ): evidence from Asperger syndrome/high-functioning autism, males and females, scientists and mathematicians. J. Autism Dev. Disord. 31, 5-17 (2001).

28. Del Bianco, T. et al. Temporal Profiles of Social Attention Are Different Across Development in Autistic and Neurotypical People. Biol Psychiatry Cogn Neurosci Neuroimaging (2020). doi:10.1016/j.bpsc.2020.09.004

29. Choi, B., Leech, K. A., Tager-Flusberg, H. \& Nelson, C. A. Development of fine motor skills is associated with expressive language outcomes in infants at high and low risk for autism spectrum disorder. J. Neurodev. Disord. 10, 14 (2018).

30. Mous, S. E., Jiang, A., Agrawal, A. \& Constantino, J. N. Attention and motor deficits 
index non-specific background liabilities that predict autism recurrence in siblings. J. Neurodev. Disord. 9, 32 (2017).

31. Müri, R. M., Iba-Zizen, M. T., Derosier, C., Cabanis, E. A. \& Pierrot-Deseilligny, C. Location of the human posterior eye field with functional magnetic resonance imaging. J. Neurol. Neurosurg. Psychiatry 60, 445-448 (1996).

770

771

772

773

774

775

776

777

778

779

780

781

782

783

784

32. Van Der Werf, J., Buchholz, V. N., Jensen, O. \& Medendorp, W. P. Neuronal synchronization in human parietal cortex during saccade planning. Behav. Brain Res. 205, 329-335 (2009).

33. Everling, S. \& Fischer, B. The antisaccade: a review of basic research and clinical studies. Neuropsychologia 36, 885-899 (1998).

34. Munoz, D. P. \& Everling, S. Look away: the anti-saccade task and the voluntary control of eye movement. Nat. Rev. Neurosci. 5, 218-228 (2004).

35. Pierrot-Deseilligny, C., Milea, D. \& Müri, R. M. Eye movement control by the cerebral cortex. Curr. Opin. Neurol. 17, 17-25 (2004).

36. Nieman, D. et al. Antisaccade task performance in patients at ultra high risk for developing psychosis. Schizophr. Res. 95, 54-60 (2007).

37. Kang, S. S., Dionisio, D. P. \& Sponheim, S. R. Abnormal mechanisms of antisaccade generation in schizophrenia patients and unaffected biological relatives of schizophrenia patients. Psychophysiology 48, 350-361 (2011).

38. Meyniel, C., Rivaud-Péchoux, S., Damier, P. \& Gaymard, B. Saccade impairments in patients with fronto-temporal dementia. J. Neurol. Neurosurg. Psychiatry 76, 1581-1584 (2005).

39. Waldthaler, J., Tsitsi, P. \& Svenningsson, P. Vertical saccades and antisaccades: complementary markers for motor and cognitive impairment in Parkinson's disease. NPJ Parkinsons Dis 5, 11 (2019).

40. Piu, P. et al. The cerebellum improves the precision of antisaccades by a latencyduration trade-off. Prog. Brain Res. 249, 125-139 (2019).

41. Muilwijk, D., Verheij, S., Pel, J. J., Boon, A. J. \& van der Steen, J. Changes in Timing 
and kinematics of goal directed eye-hand movements in early-stage Parkinson's disease. Transl. Neurodegener. 2, 1 (2013).

42. Clayton, E. et al. A crucial role for the p110delta subunit of phosphatidylinositol 3-kinase in B cell development and activation. J. Exp. Med. 196, 753-763 (2002).

43. Bishop, J. C. \& Pangelinan, M. Motor skills intervention research of children with disabilities. Res. Dev. Disabil. 74, 14-30 (2018).

44. Mostofsky, S. H. et al. Decreased connectivity and cerebellar activity in autism during motor task performance. Brain 132, 2413-2425 (2009).

45. Vinueza Veloz, M. F. et al. Cerebellar control of gait and interlimb coordination. Brain Struct. Funct. 220, 3513-3536 (2015).

46. Kayan Ocakoglu, B., Karaca, N. E., Ocakoglu, F. T. \& Erermis, S. Psychological burden of pediatric primary immunodeficiency. Pediatr. Int. 60, 911-917 (2018).

47. Cross, A. J., Goharpey, N., Laycock, R. \& Crewther, S. G. Anxiety as a Common Biomarker for School Children With Additional Health and Developmental Needs Irrespective of Diagnosis. Front. Psychol. 10, 1420 (2019).

48. North, C. R., Wild, T. C., Zwaigenbaum, L. \& Colman, I. Early neurodevelopment and self-reported adolescent symptoms of depression and anxiety in a National Canadian Cohort Study. PLoS One 8, e56804 (2013).

49. MacDuffie, K. E. et al. Sleep Problems and Trajectories of Restricted and Repetitive Behaviors in Children with Neurodevelopmental Disabilities. J. Autism Dev. Disord. (2020). doi:10.1007/s10803-020-04438-y

814 50. Tsai, P. T. et al. Autistic-like behaviour and cerebellar dysfunction in Purkinje cell Tsc1 815 mutant mice. Nature 488, 647-651 (2012).

816 51. Stoodley, C. J. et al. Altered cerebellar connectivity in autism and cerebellar-mediated rescue of autism-related behaviors in mice. Nat. Neurosci. 20, 1744-1751 (2017).

818 52. Badura, A. et al. Normal cognitive and social development require posterior cerebellar 819 activity. Elife 7, (2018).

820 53. Siegel, M. S. \& Smith, W. E. Psychiatric features in children with genetic syndromes: 
toward functional phenotypes. Child Adolesc. Psychiatr. Clin. N. Am. 19, 229-61, viii (2010).

54. Brown, K. A., Parikh, S. \& Patel, D. R. Understanding basic concepts of developmental diagnosis in children. Transl Pediatr 9, S9-S22 (2020).

55. Yang, M., Silverman, J. L. \& Crawley, J. N. Automated three-chambered social approach task for mice. Curr. Protoc. Neurosci. Chapter 8, Unit 826 (2011).

56. Datta, S. R., Anderson, D. J., Branson, K., Perona, P. \& Leifer, A. Computational Neuroethology: A Call to Action. Neuron 104, 11-24 (2019).

57. Berman, G. J. Measuring behavior across scales. BMC Biol. 16, 23 (2018).

58. Machado, A. S., Marques, H. G., Duarte, D. F., Darmohray, D. M. \& Carey, M. R. Shared and specific signatures of locomotor ataxia in mutant mice. Neuroscience 18 (2020).

59. Forkosh, O. et al. Identity domains capture individual differences from across the behavioral repertoire. Nat. Neurosci. 22, 2023-2028 (2019).

60. Deverman, B. E. \& Patterson, P. H. Cytokines and CNS development. Neuron 64, 6178 (2009).

61. Cowan, M. \& Petri, W. A., Jr. Microglia: Immune Regulators of Neurodevelopment. Front. Immunol. 9, 2576 (2018).

62. Pape, K., Tamouza, R., Leboyer, M. \& Zipp, F. Immunoneuropsychiatry - novel perspectives on brain disorders. Nat. Rev. Neurol. 15, 317-328 (2019).

63. Ahmed, A. A., El Shahaway, A. A. \& Hussien, S. A. Activated PI3K-delta syndrome in an Egyptian pediatric cohort with primary immune deficiency. Allergol. Immunopathol. (2020). doi:10.1016/j.aller.2019.12.006

64. Ming, X., Brimacombe, M. \& Wagner, G. C. Prevalence of motor impairment in autism spectrum disorders. Brain Dev. 29, 565-570 (2007).

65. Law, A. J. et al. Neuregulin 1-ErbB4-PI3K signaling in schizophrenia and phosphoinositide 3-kinase-p110ס inhibition as a potential therapeutic strategy. Proc. Natl. Acad. Sci. U. S. A. 109, 12165-12170 (2012). 
849 66. La Manno, G. et al. Molecular architecture of the developing mouse brain. Cold Spring Harbor Laboratory 2020.07.02.184051 (2020). doi:10.1101/2020.07.02.184051

67. Rosina, E. et al. Disruption of mTOR and MAPK pathways correlates with severity in idiopathic autism. Transl. Psychiatry 9, 50 (2019).

68. Mühlebner, A., Bongaarts, A., Sarnat, H. B., Scholl, T. \& Aronica, E. New insights into a spectrum of developmental malformations related to mTOR dysregulations: challenges and perspectives. J. Anat. 235, 521-542 (2019).

69. Tsai, P. T. et al. Sensitive Periods for Cerebellar-Mediated Autistic-like Behaviors. Cell Rep. 25, 357-367.e4 (2018).

70. Shi, L., Fatemi, S. H., Sidwell, R. W. \& Patterson, P. H. Maternal influenza infection causes marked behavioral and pharmacological changes in the offspring. J. Neurosci. 23, 297-302 (2003).

71. Haida, O. et al. Sex-dependent behavioral deficits and neuropathology in a maternal immune activation model of autism. Transl. Psychiatry 9, 124 (2019).

72. Amodeo, D. A. et al. Maternal immune activation impairs cognitive flexibility and alters transcription in frontal cortex. Neurobiol. Dis. 125, 211-218 (2019).

73. Sabourin, K. R. et al. Infections in children with autism spectrum disorder: Study to Explore Early Development (SEED). Autism Res. 12, 136-146 (2019).

74. Lee, B. K. et al. Maternal hospitalization with infection during pregnancy and risk of autism spectrum disorders. Brain Behav. Immun. 44, 100-105 (2015).

75. Atladóttir, H. O. et al. Maternal infection requiring hospitalization during pregnancy and autism spectrum disorders. J. Autism Dev. Disord. 40, 1423-1430 (2010).

76. Patel, S. et al. Social impairments in autism spectrum disorder are related to maternal immune history profile. Mol. Psychiatry 23, 1794-1797 (2018).

77. Yildirim, M. et al. Neurologic Involvement in Primary Immunodeficiency Disorders. J. Child Neurol. 33, 320-328 (2018).

875 78. Subbarayan, A. et al. Clinical features that identify children with primary 876 immunodeficiency diseases. Pediatrics 127, 810-816 (2011). 
877

878

879

880

881

882

883

884

885

886

887

888

889

890

891

892

893

894

895

896

897

898

899

900

901

902

903

904

79. Sgritta, M. et al. Mechanisms Underlying Microbial-Mediated Changes in Social Behavior in Mouse Models of Autism Spectrum Disorder. Neuron 101, 246-259.e6 (2019).

80. Qiao, Y. et al. Alterations of oral microbiota distinguish children with autism spectrum disorders from healthy controls. Sci. Rep. 8, 1597 (2018).

81. Carissimi, C. et al. Functional analysis of gut microbiota and immunoinflammation in children with autism spectrum disorders. Dig. Liver Dis. 51, 1366-1374 (2019).

82. Sun, H., You, Z., Jia, L. \& Wang, F. Autism spectrum disorder is associated with gut microbiota disorder in children. BMC Pediatr. 19, 516 (2019).

83. Kang, D.-W. et al. Long-term benefit of Microbiota Transfer Therapy on autism symptoms and gut microbiota. Sci. Rep. 9, 5821 (2019).

84. Preite, S. et al. Hyperactivated PI3Kס promotes self and commensal reactivity at the expense of optimal humoral immunity. Nat. Immunol. 19, 986-1000 (2018).

85. Steinbach, E. C. et al. Innate PI3K p110ס regulates Th1/Th17 development and microbiota-dependent colitis. J. Immunol. 192, 3958-3968 (2014).

86. Oka, A. et al. Phosphoinositide 3-Kinase P110ס-Signaling Is Critical for MicrobiotaActivated IL-10 Production by B Cells that Regulate Intestinal Inflammation. Cells 8, (2019).

87. Meltzer, A. \& Van de Water, J. The Role of the Immune System in Autism Spectrum Disorder. Neuropsychopharmacology 42, 284-298 (2017).

88. Nazeen, S., Palmer, N. P., Berger, B. \& Kohane, I. S. Integrative analysis of genetic data sets reveals a shared innate immune component in autism spectrum disorder and its co-morbidities. Genome Biol. 17, 228 (2016).

89. Tippett, W. J. \& Sergio, L. E. Visuomotor integration is impaired in early stage Alzheimer's disease. Brain Res. 1102, 92-102 (2006).

90. Inzelberg, R., Schechtman, E. \& Hocherman, S. Visuo-motor coordination deficits and motor impairments in Parkinson's disease. PLoS One 3, e3663 (2008).

91. de Boer, C., van der Steen, J., Mattace-Raso, F., Boon, A. J. W. \& Pel, J. J. M. The 
Effect of Neurodegeneration on Visuomotor Behavior in Alzheimer's Disease and Parkinson's Disease. Motor Control 20, 1-20 (2016).

92. Pel, J. J. M. et al. Early identification of cerebral visual impairments in infants born extremely preterm. Dev. Med. Child Neurol. 58, 1030-1035 (2016).

909

910

911

912

913

914

915

916

917

918

919

920

921

922

923

924

925

926

927

928

929

930

931

932

93. Ben-Shaul, Y. OptiMouse: a comprehensive open source program for reliable detection and analysis of mouse body and nose positions. BMC Biol. 15, 41 (2017).

94. van den Boom, B. J. G., Pavlidi, P., Wolf, C. J. H., Mooij, A. H. \& Willuhn, I. Automated classification of self-grooming in mice using open-source software. J. Neurosci. Methods 289, 48-56 (2017).

95. Ueno, H. et al. Effects of repetitive gentle handling of male C57BL/6NCrl mice on comparative behavioural test results. Sci. Rep. 10, 3509 (2020).

96. Sonzogni, M. et al. A behavioral test battery for mouse models of Angelman syndrome: a powerful tool for testing drugs and novel Ube3a mutants. Mol. Autism 9, 47 (2018).

97. Reith, R. M., Way, S., McKenna, J., 3rd, Haines, K. \& Gambello, M. J. Loss of the tuberous sclerosis complex protein tuberin causes Purkinje cell degeneration. Neurobiol. Dis. 43, 113-122 (2011).

98. Duda, R. O., Hart, P. E. \& Stork, D. G. Pattern classification and scene analysis. 3, (Wiley New York, 1973).

99. Gomez, M. J. et al. Comparison of methods for outlier detection and their effects on the classification results for a particular data base. Anal. Chim. Acta 239, 229-243 (1990).

100.Ng, M. K., Liao, L.-Z. \& Zhang, L. On sparse linear discriminant analysis algorithm for high-dimensional data classification. Numer. Linear Algebra Appl. 18, 223-235 (2011).

101.Landau, D. P. \& Binder, K. A Guide to Monte Carlo Simulations in Statistical Physics. (Cambridge University Press, 2005).

102. Vries, E. de et al. Immulogie in de medische praktijk. XXXIV. Diagnostiek bij vermoeden van een afweerstoornis: inleiding. (2000). at <https://repository.ubn.ru.nl/handle/2066/144811>

103. Comans-Bitter, W. M. et al. Immunophenotyping of blood lymphocytes in childhood. 
bioRxiv preprint doi: https://doi.org/10.1101/2021.01.15.426862; this version posted January 16, 2021. The copyright holder for this preprint (which was not certified by peer review) is the author/funder, who has granted bioRxiv a license to display the preprint in perpetuity. It is made available under aCC-BY-NC-ND 4.0 International license. 


\section{Figures}

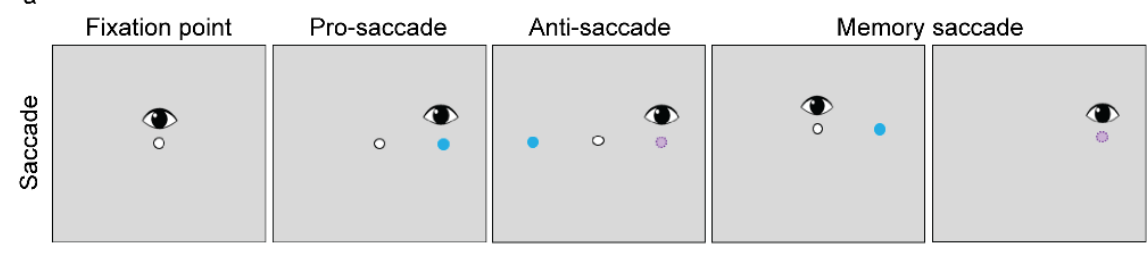

b Fixation point

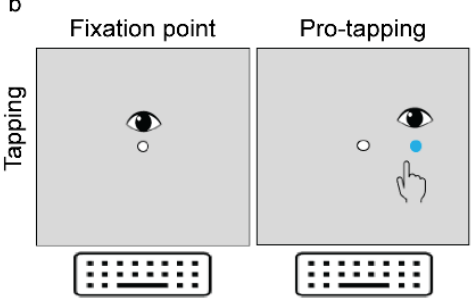

Anti-tapping

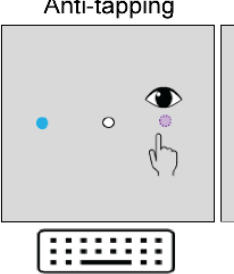

::::::
Memory tapping

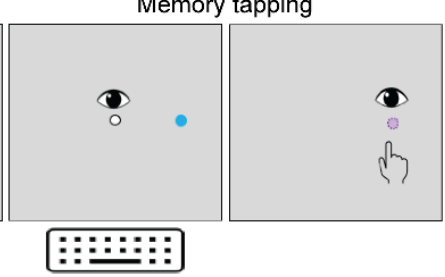

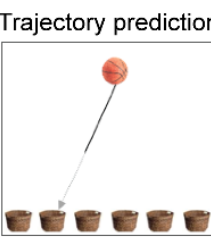

$::::::::$

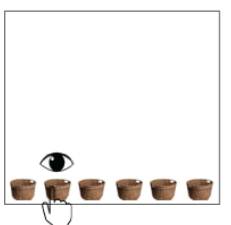

Figure 1: Visuomotor assessment tasks. Visual representation of the saccade (a), tapping (b) and trajectory prediction (c) tasks performed by patients P1 and P2, and respective agematched controls. Pro- tasks involved the execution of reflexive saccades (and tapping) towards a newly appeared target while anti- tasks required a saccade execution (and tapping) to the opposite side of the new target. In memory tasks, subjects waited for target omission to perform a saccade (and tapping). Trajectory prediction tasks involved the execution of a saccade and tapping towards the basket in which a moving ball would be expected to fall. The number and age distribution of control participants per task can be found in Table 3. 
a

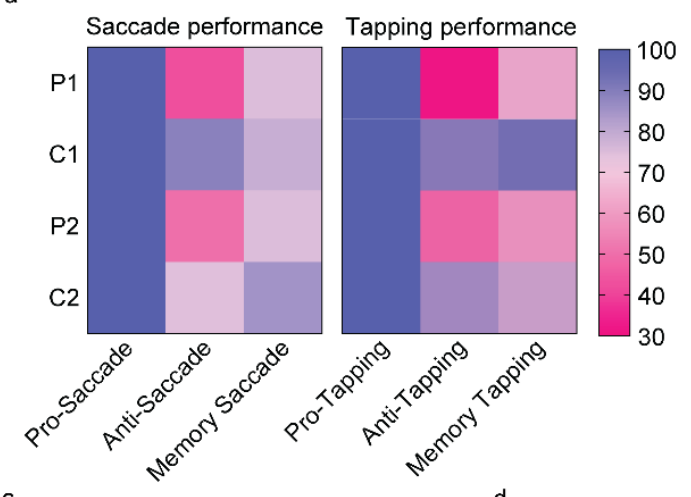

C

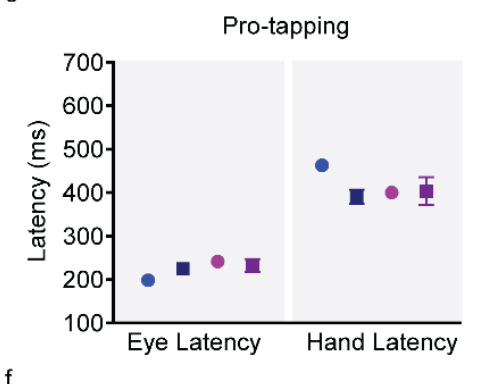

d
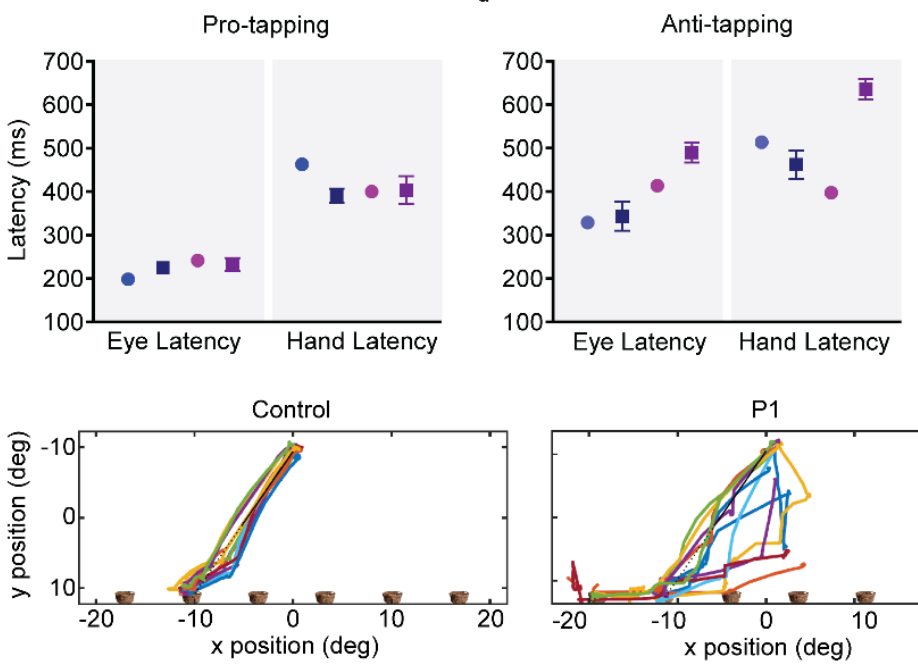

b

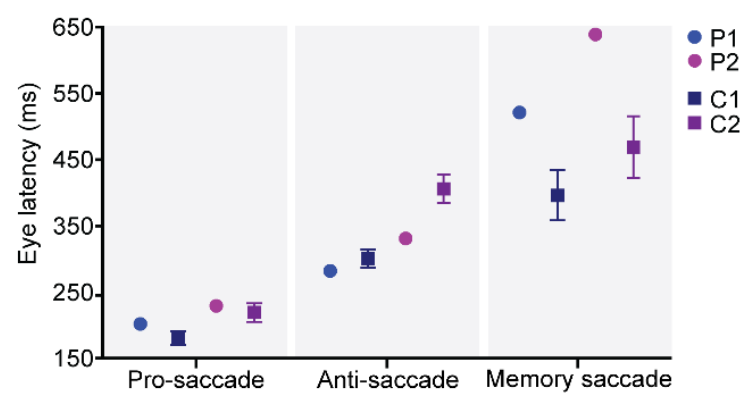

e
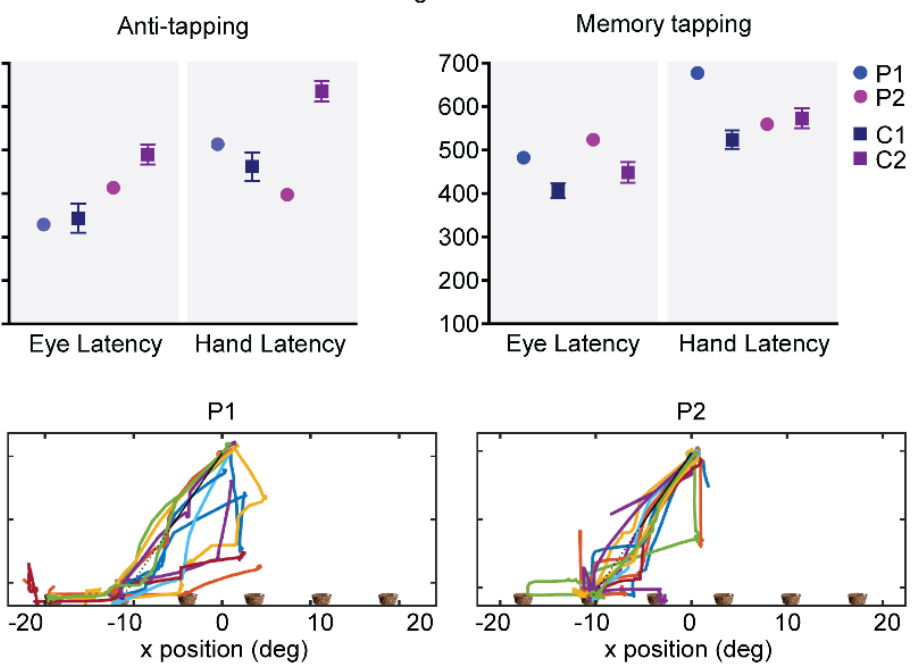

Figure 2: APDS patients present with intact reflexive saccades but altered integration. a) Performance in the saccade and tapping tasks is presented as percentage of correct trials. Eye latency for the saccade tasks (b), and eye and hand latency for the tapping tasks (c-e) are presented in ms. f) Representative traces of the eye trajectories performed towards one basket, during the trajectory prediction task. P1, patient 1, P2, patient 2; C1, age-matched controls for patient 1, C2, age-matched controls for patient 2. 
a

Tracked body position

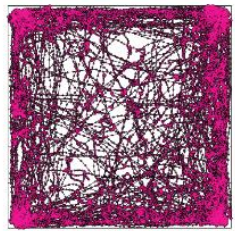

Wild-type
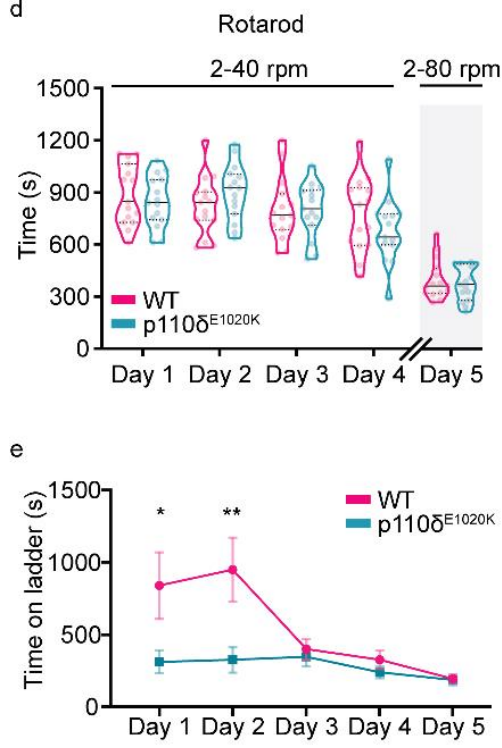

b Mean speed $(\mathrm{cm} / \mathrm{s})$

c
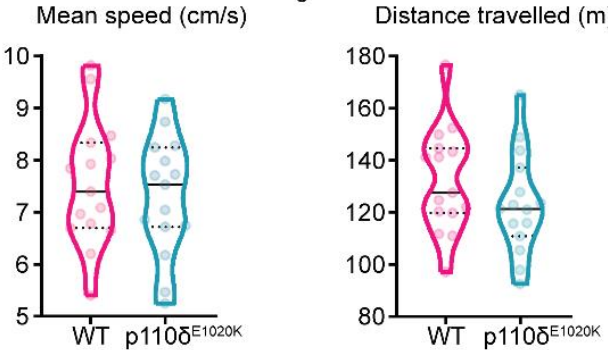

f

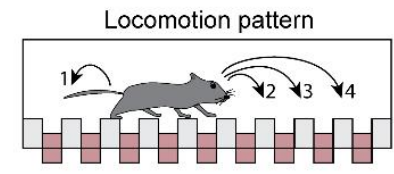

Backsteps

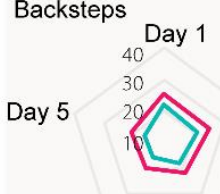

Day 4

Day 3

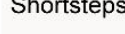

Day 1

Day 2 Day 5

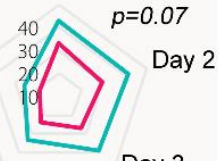

Day 4

Day 3

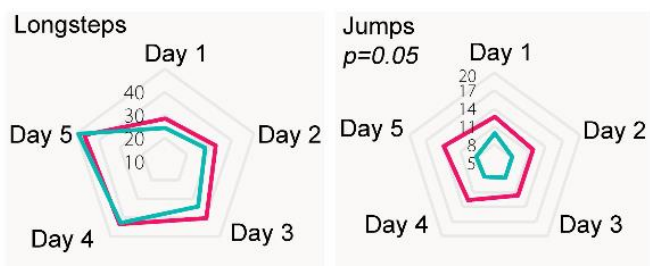

Figure 3: Slight fine locomotion impairments are caused by the murine E1020K mutation. a) Example of automatically tracked trajectories showing the body position of a WT and a p $110 \delta^{E 1020 K}$ mouse during the 30 minutes of the OF task. b-c) Quantification of the mean speed $\left(n=15\right.$ per genotype) and total distance travelled $\left(n=15\right.$ WT and $\left.14 p 110 \delta^{E 1020 K}\right)$ during the OF task, presented as median and quartiles (2-tailed t-test). $d$ ) The total time each mouse spent on the rotarod, over the course of 4 trials/day, is presented as median and quartiles (2way repeated-measures ANOVA, $n=15$ per genotype). On the last day, the maximum rod speed was increased to $80 \mathrm{rpm}$. e-g) The Erasmus ladder was used to investigate locomotion pattern. The average time each mouse spent on the ladder, across 42 daily trials, is presented in (e) (2-tailed Mann-Whitney; data presented as mean \pm SEM). The distinct step types analysed are schematically represented in ( $f$ ) and quantified in ( $g$ ) (Mixed effects model; data is presented as daily mean percentage, $n=15$ per genotype). ${ }^{*} p \leq 0.05,{ }^{* *} p \leq 0.01,{ }^{* * *} p \leq 0.001$. 


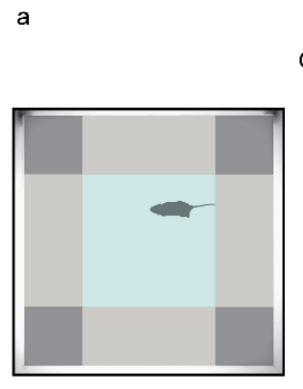

b

Open-Field

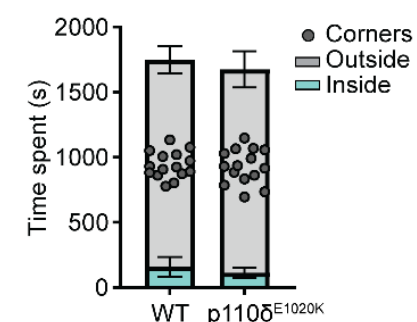

d

Elevated-Plus Maze
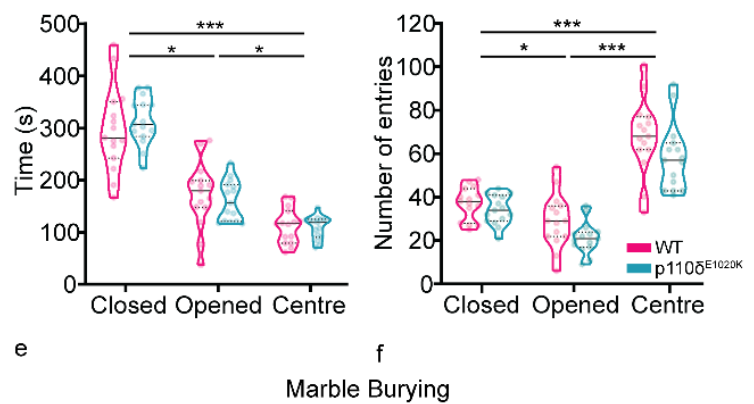

Marble Burying
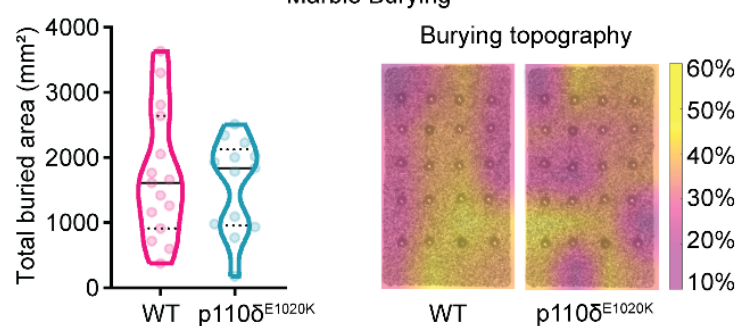
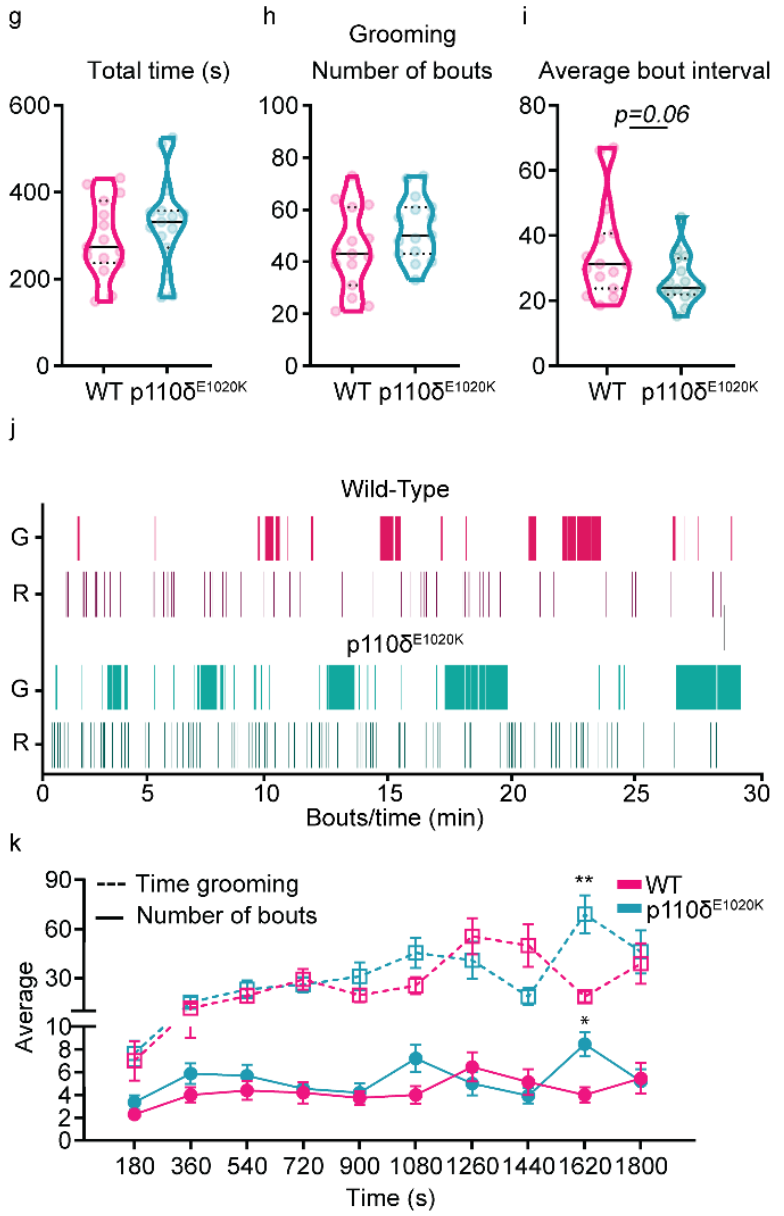

Figure 4: $\mathbf{p} 110 \delta^{\mathrm{E} 1020 \mathrm{~K}}$ mice exhibit subtle changes in burying and grooming patterns. a) Representation of the OF arena parcellation into corner, outside and inside areas. b) Total time spent on each OF area (2-tailed Mann-Whitney; data presented as mean \pm SD). c-d) Total time spent and number of entries performed in each EPM area (2-way repeatedmeasures ANOVA; data are presented as median and quartiles). e) Total marble area buried during the MB task (2-tailed t-test). f) Marble disposition before the task, superimposed with the average percentage of buried area per marble ( $n=15$ WT and $\left.\left.n=13 p 110 \delta^{E 1020 K}\right) . g-i\right)$ Quantification of the total time spent grooming $(\mathrm{g})$, total number of grooming bouts $(\mathrm{h})$ and the average time interval between grooming bouts (i), during the grooming assay (2-tailed t-test; data presented as median and quartiles). j) Representative plot depicting grooming and rearing events for one mouse of each genotype. k) Time-binned plot with the average time spent grooming (dashed line; 2-way repeated-measures ANOVA) and the average number of grooming bouts (full line; mixed effects model) (data are presented as mean \pm SEM). $G$, grooming, $R$, rearing; ${ }^{*} p \leq 0.05,{ }^{* *} p \leq 0.01,{ }^{* * *} p \leq 0.001, n=15$ mice per genotype, expect for e) and f) (see above). 

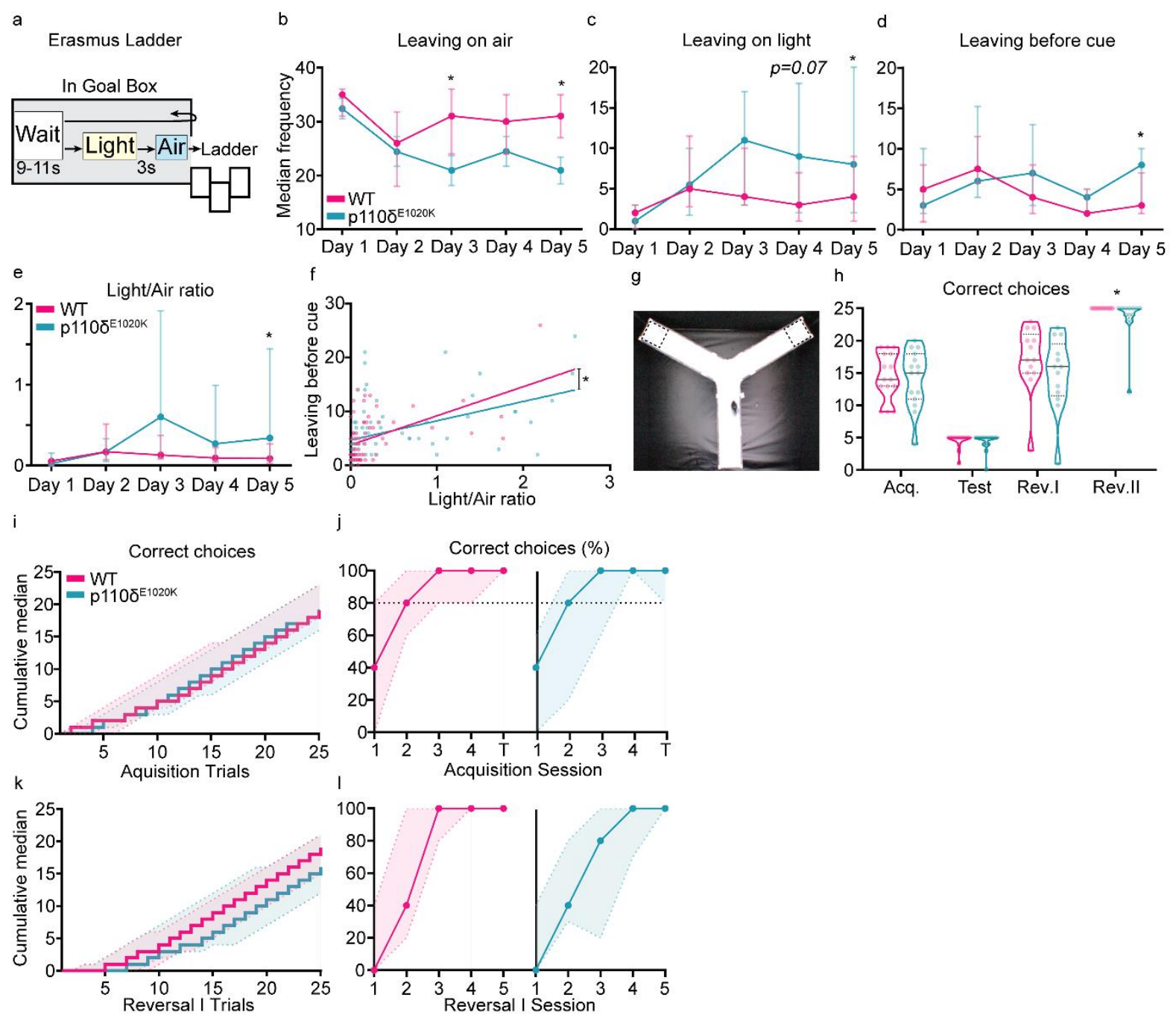

Figure 5: Stimulus-dependent ladder exit and reversal learning are mildly affected in p110 ${ }^{\mathrm{E} 1020 \mathrm{~K}}$ mice. a) Schematic of the Erasmus ladder goal-box with the time intervals between stimuli. b-d) Number of times individual mice left the goal-box with the air stimulus (b), the light stimulus (c), or before light cue presentation (d). e) ratio between light and air exits. f) Best-fit regression model between the data points used to plot (d) and (e).g) Picture of the Y-Maze, with dashed squares representing the possible locations for the hidden platform, either on the right or left arm of the apparatus. h) Total number of correct arm choices for both genotypes, during each phase of the Y-Maze (data presented as median with interquartile range). i) Step function with the cumulative median and interquartile range for the number of correct arm choices during all acquisition and test trials. j) Percentage of correct arm choices for each genotype over the four days of acquisition and the day of test (data presented as median with interquartile range) $k-I$ ) Similar to (i) and (j) but for the reversal I phase. 2-tailed Mann-Whitney, except for f). ${ }^{*} p \leq 0.05, n=15$ mice per genotype, except for reversal phases where $n=13$. 
a

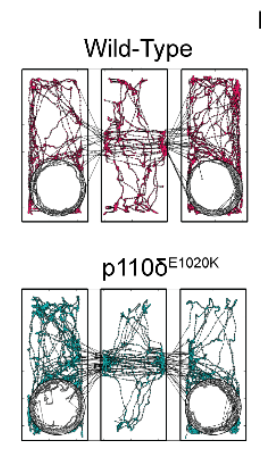

b

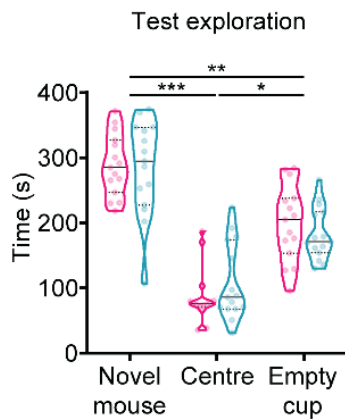

c

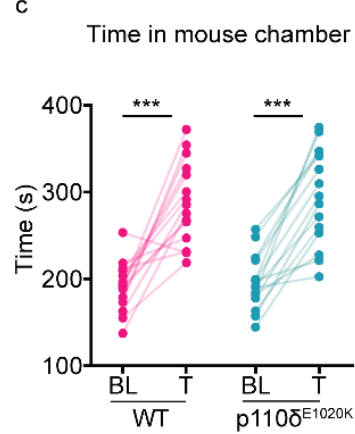

d

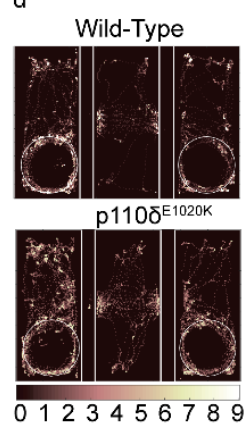

Social cup preference

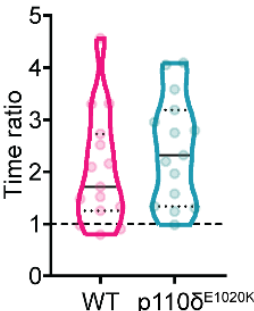

f

Transitions to cups during test
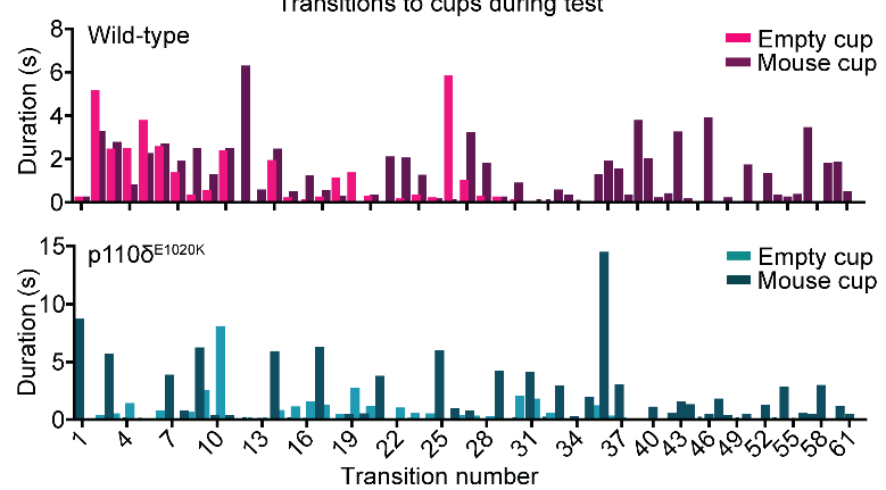

g

Social Investigation

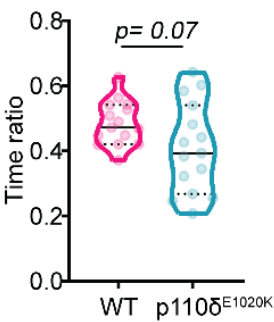

Figure 6: Social behaviour is largely preserved in $\mathrm{p} 110 \delta^{\mathrm{E} 1020 \mathrm{~K}}$ mice. a) Example of automatically tracked body positions during test phase (novel mouse on the left). b) Total time individual mice spent in each chamber of the apparatus during test phase (mixed effects model; data presented as median with interquartile range). c) Before and after plot of the total time each individual mouse spent on the novel mouse chamber during baseline (BL) and test (T) (2-way repeated-measures ANOVA). d) Body position heatmap depicting position frequency per $2.5 \mathrm{~mm}$ bins (novel mouse on the left). e) Median and quartiles with the ratio between the time each individual mouse spent near the social cup over the time it spent near the empty cup (2-tailed t-test). f) Representative plot with the duration, in seconds, of each transition into the empty (light bars) or novel mouse (dark bars) cup area. g) Median and quartiles with the percentage of transitions each individual mouse made to the novel mouse or empty cup (2-way repeated-measures ANOVA); h) Median and quartiles of the ratio between the time individual mice spent exploring the novel mouse cup over the time spent in the whole novel mouse chamber (2-tailed t-test). ${ }^{*} p \leq 0.05,{ }^{* *} p \leq 0.01,{ }^{* * *} p \leq 0.001 . n=15$ mice per genotype. 
a Absolute feature contribution per LD $(\%)$

\begin{tabular}{|c|c|c|c|}
\hline & & LD1 & LD2 \\
\hline & Jumps & 2.19 & 5.45 \\
\hline \multirow{6}{*}{$\vec{\omega}$} & Leave bef. cue & 3.55 & 0.96 \\
\hline & Light/air exits & 8.92 & 1.22 \\
\hline & Missteps & 3.98 & 2.45 \\
\hline & Shortsteps & 0.95 & 2.76 \\
\hline & Time on ladder & 9.23 & 0.61 \\
\hline & Trial duration & 0.70 & 5.81 \\
\hline \multirow{3}{*}{ 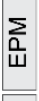 } & Time closed arm & 0.31 & 1.39 \\
\hline & Total distance & 5.09 & 7.39 \\
\hline & Total transitions & 3.61 & 2.13 \\
\hline \multirow{4}{*}{0} & Long bouts & 1.73 & 0.01 \\
\hline & Total bouts & 4.99 & 3.86 \\
\hline & Total time & 8.52 & 4.14 \\
\hline & Rearing bouts & 1.23 & 0.65 \\
\hline$\Sigma$ & Area buried & 6.27 & 0.03 \\
\hline \multirow{3}{*}{0} & Time outside & 1.25 & 4.86 \\
\hline & Total distance & 2.71 & 0.63 \\
\hline & Total transitions & 2.89 & 0.92 \\
\hline$\llbracket$ & Time on rod & 0.68 & 1.80 \\
\hline \multirow{7}{*}{$\bar{\omega}$} & Ratio cup tran.T & 2.16 & 1.47 \\
\hline & SC preference & 3.24 & 0.12 \\
\hline & SI preference & 1.47 & 3.87 \\
\hline & Distance BL & 4.55 & 5.07 \\
\hline & Distance T & 0.98 & 11.60 \\
\hline & Transitions BL & 3.61 & 2.68 \\
\hline & Transitions T & 1.70 & 9.53 \\
\hline \multirow{5}{*}{$\sum_{>}$} & Acquisition & 5.00 & 3.07 \\
\hline & Reversal I & 3.22 & 5.47 \\
\hline & Correct choices & 1.24 & 2.95 \\
\hline & Total distance & 0.94 & 0.51 \\
\hline & Plat. not reac. & 3.09 & 6.58 \\
\hline
\end{tabular}

b LDA- 10 best features' contributions

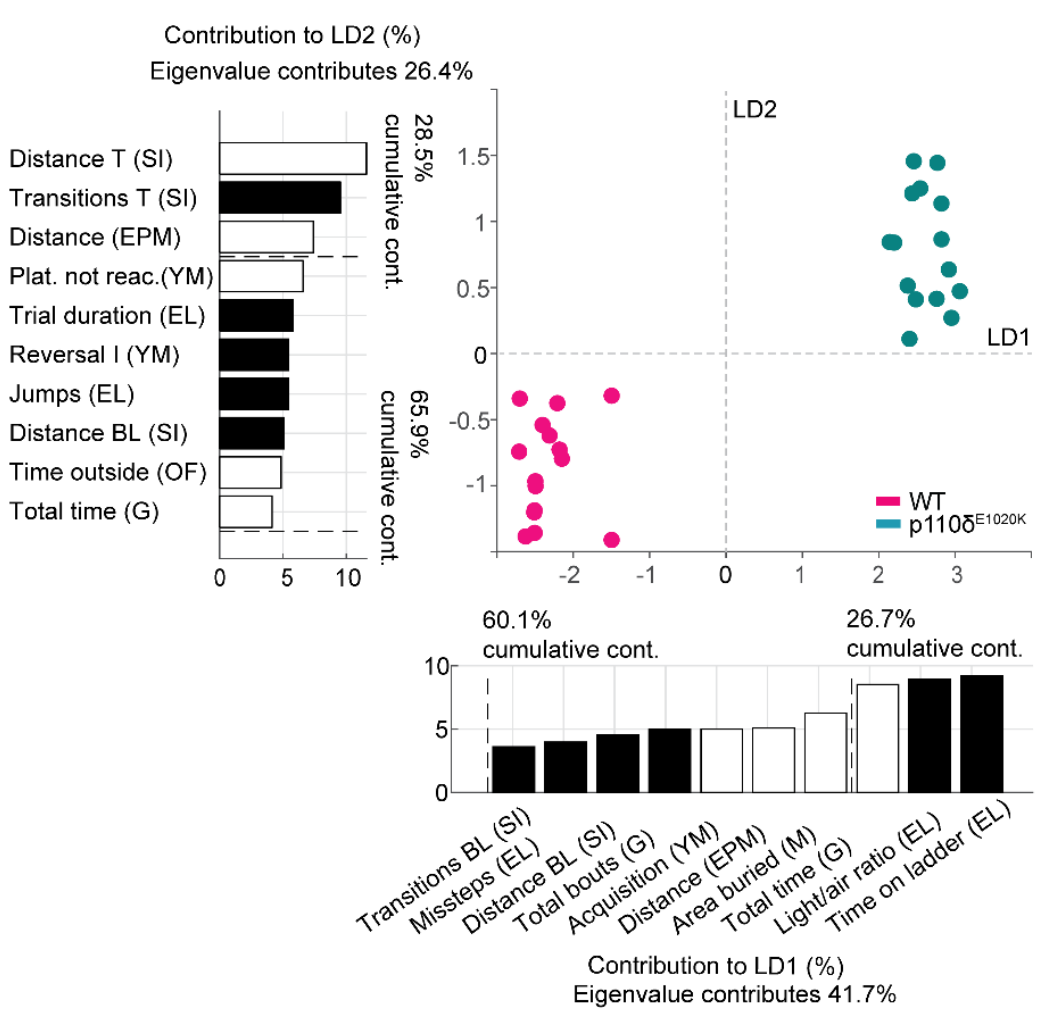

Figure 7: LD1 and LD2 features separate WT from p110 ${ }^{\mathrm{E} 1020 \mathrm{~K}}$ mice. a) Absolute contribution of each behavioural variable, in percentage, to linear discriminants 1 and 2 , resulting from the LDA. b) LDA plot featuring the 10 best contributors to LD1 and LD2. Negative and positive contributions are represented by black and white bars, respectively. Each dot represents one mouse, with pink dots representing WT mice and green dots p110 $\delta^{\mathrm{E} 1020 \mathrm{~K}}$ mice. $\mathrm{n}=15$ mice per genotype. EL, Erasmus ladder, EPM, elevated-plus maze, $\mathrm{G}$, grooming, M, marble burying, OF, open-field, R, rotarod, SI, social interaction, YM, water y-maze. 
bioRxiv preprint doi: https://doi.org/10.1101/2021.01.15.426862; this version posted January 16,2021 . The copyright holder for this preprint (which was not certified by peer review) is the author/funder, who has granted bioRxiv a license to display the preprint in perpetuity. It is made available under aCC-BY-NC-ND 4.0 International license.

\section{Tables}

\begin{tabular}{|c|c|c|}
\hline Sex & Male (P1) & Female (P2) \\
\hline $\begin{array}{l}\text { Age } \\
\text { (diagnosis) }\end{array}$ & 29 (3.5 years) & 56 (childhood) \\
\hline Mutation & E1021K & $\mathrm{E} 1021 \mathrm{~K}$ \\
\hline $\begin{array}{l}\text { Response to } \\
\text { immunization }\end{array}$ & $\downarrow S$. pneumonia (polysaccharide response) & $\downarrow$ Influenza type A and type B \\
\hline $\begin{array}{l}\text { Hepato/spleno } \\
\text { megaly }\end{array}$ & Splenomegaly & Absent \\
\hline Cytopenia & Leucopenia, thrombocytopenia & None \\
\hline $\begin{array}{l}\text { CT-chest } \\
\text { results }\end{array}$ & Air trapping, no bronchiectasis & Bronchiectasis \\
\hline $\begin{array}{l}\text { Hematological } \\
\text { malignancy }\end{array}$ & No & No \\
\hline $\begin{array}{l}\text { Other } \\
\text { comorbidities }\end{array}$ & $\begin{array}{l}\text { Psychomotor developmental delay } \\
\text { SLE-like auto-immune disease } \\
\text { Recurrent EBV infections } \\
\text { Autoimmune hepatitis with liver cirrhosis and portal } \\
\text { hypertension }\end{array}$ & None \\
\hline Ig therapy & $\begin{array}{l}\text { Intravenous Ig replacement therapy: } 35 \mathrm{~g} \text {, every } 3 \\
\text { weeks }\end{array}$ & $\begin{array}{l}\text { Intravenous Ig replacement therapy: } 15 \mathrm{~g} \text {, every } \\
4 \text { weeks }\end{array}$ \\
\hline $\begin{array}{l}\text { Other relevant } \\
\text { treatments }\end{array}$ & $\begin{array}{l}\text { Prednisone: } 10 \mathrm{mg} \text {, once daily } \\
\text { Mycophenolate mofetil: } 500 \mathrm{mg} \text {, twice daily } \\
\text { Hydroxychloroquine: } 200 \mathrm{mg} \text {, once daily } \\
\text { Trimethoprim/sulfamethoxazole: } 480 \mathrm{mg} \text {, once daily }\end{array}$ & $\begin{array}{l}\text { No immunosuppressive medication } \\
\text { No prophylactic antibiotics }\end{array}$ \\
\hline
\end{tabular}

Table 1: P1 and P2 clinical characteristics. SLE, systemic lupus erythematosus; $\downarrow$, decreased compared to control age-matched range. 


\begin{tabular}{|c|c|c|}
\hline Patient & $\mathrm{P} 1$ & $\mathrm{P} 2$ \\
\hline $\begin{array}{l}\text { Ig at diagnosis } \\
(\mathrm{g} / \mathrm{L} ; \text { range }(102))\end{array}$ & $\begin{array}{l}\lg G 0.46(4.0-11.0), \lg A 0.45(0.1-1.6), \\
\lg M 3.24(0.5-1.8)\end{array}$ & Unknown \\
\hline $\begin{array}{l}\text { T/B/NK cells at diagnosis } \\
\left(\text { abs } \times 10^{9} / \mathrm{L} ; \text { range }(103)\right)\end{array}$ & $\begin{array}{l}\text { T cells } 3.66(0.9-4.5), \text { CD4}^{+} \mathbf{T} \text { cells } 0.51 \\
(0.5-2.4), \text { CD8 }^{+} \mathbf{T} \text { cells } 3.15(0.3-1.6), \mathrm{B} \\
\text { cells } 0.26(0.2-2.1), \mathrm{NK}^{-} \text {cells } 0.26(0.1- \\
1.0)\end{array}$ & Unknown \\
\hline $\begin{array}{l}\text { T/B/NK cells } \\
\left(\text { abs } \times 10^{9} / L ; \text { range }(103)\right) \\
\text { [B cell subsets in abs, cells/ul] }\end{array}$ & 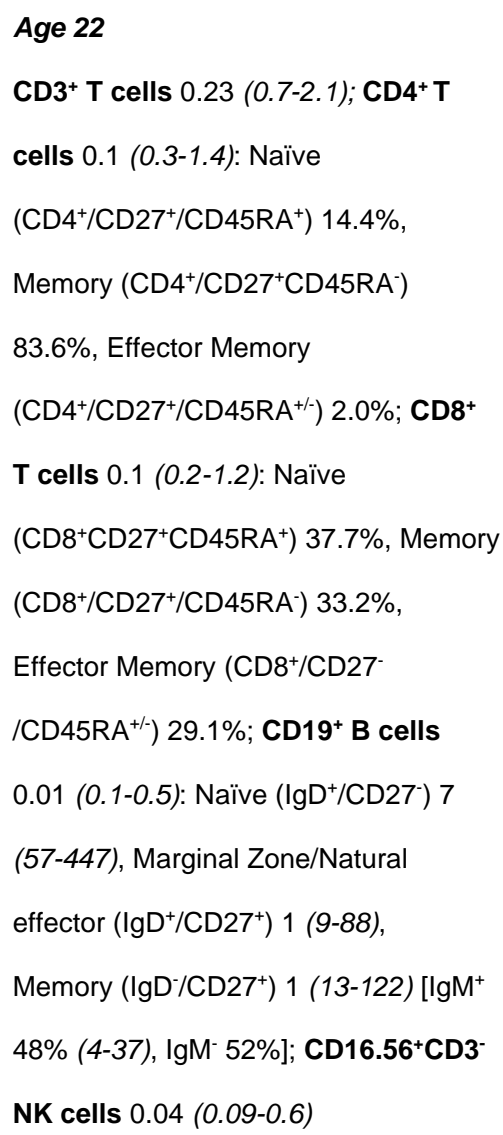 & $\begin{array}{l}\text { Age } 43 \\
\text { CD3 }^{+} \text {T cells } 0.53(0.7-2.1) \\
\text { CD19+ B cells } 0.09(0.1-0.5): \\
\text { CD16.56+CD3- NK cells } 0.15(0.09-0.6)\end{array}$ \\
\hline $\lg (\mathrm{g} / \mathrm{L} ;$ range (102)) & $\begin{array}{l}\text { Age } 28 \\
\operatorname{lgG} 12.0(6.0-12.3), \lg \mathrm{A} 0.43(0.3-2.0), \\
\operatorname{lgM} 3.24(0.5-2.0)\end{array}$ & $\begin{array}{l}\text { Age } 55 \\
\operatorname{lgG} 16.6(6.0-12.3), \lg \mathrm{A} 1.49(0.3-2.0), \\
\operatorname{lgM} 4.75(0.5-2.0)\end{array}$ \\
\hline
\end{tabular}

Table 2: P1 and P2 immunological findings. Abs, absolute numbers; $\downarrow$, decreased compared to control age-matched range. 
bioRxiv preprint doi: https://doi.org/10.1101/2021.01.15.426862; this version posted January 16,2021 . The copyright holder for this preprint (which was not certified by peer review) is the author/funder, who has granted bioRxiv a license to display the preprint in perpetuity. It is made available under aCC-BY-NC-ND 4.0 International license.

\begin{tabular}{|c|c|c|c|c|c|c|}
\hline \multirow{2}{*}{ Visuomotor assessment } & \multicolumn{3}{|c|}{ Control 1} & \multicolumn{3}{|c|}{ Control 2} \\
\hline & $\begin{array}{c}\text { Age } \\
\text { (average, years) }\end{array}$ & SD & $\mathrm{N}$ & $\begin{array}{c}\text { Age } \\
\text { (average, years) }\end{array}$ & SD & $\mathrm{N}$ \\
\hline Pro-saccade & 24,82 & 5,04 & 12 & 54,00 & 13,39 & 11 \\
\hline Anti-saccade & 25,00 & 3,35 & 14 & 57,70 & 8,66 & 17 \\
\hline Memory saccade & 24,84 & 5,28 & 11 & 45,70 & 7,27 & 10 \\
\hline Pro-tapping & 24,76 & 3,88 & 10 & 56,80 & 13,11 & 10 \\
\hline Anti-tapping & 24,90 & 7,06 & 10 & 55,96 & 7,68 & 28 \\
\hline Memory tapping & 25,47 & 5,67 & 10 & 53,62 & 6,31 & 16 \\
\hline Trajectory prediction* & 38,30 & 8,78 & 10 & NA & NA & NA \\
\hline
\end{tabular}

Table 3: Characteristics of controls. Age-matched individuals were tested in visuomotor assessment tasks and used as controls for patient 1 or patient 2. * for the trajectory prediction task, only one control group was used. 